\title{
A ocorrência alcalina de Cananéia, litoral sul do estado de São Paulo: petrologia e geoquímica
}

\author{
Fernando Pelegrini Spinelli' \& Celso de Barros Gomes ${ }^{2}$
}

\begin{abstract}
Resumo O maciço de Cananéia (Ar-Ar, 83,6 $\pm 0,9 \mathrm{Ma}$ ), SE do Brasil, é representado por dois pequenos corpos - Morro de São João, 1,8 km², e Morrete, 0,4 km². A intrusão é coberta por sedimentos quaternários, tem como encaixante rochas do Grupo Açungui e está tectonicamente associada ao Arco de Ponta Grossa (Lineamento de Guapiara). Rochas sieníticas reunidas em dois grupos, álcali feldspato sienitos e quartzo-álcali feldspato sienitos, são dominantes e microssienitos, subordinados. Feldspato alcalino (mesopertita), quartzo, clinopiroxênio, anfibólio e biotita são os minerais mais comuns, enquanto que plagioclásio e olivina ocorrem raramente. Como acessórios estão presentes minerais opacos, apatita, titanita e zircão. As rochas de Cananéia são saturadas a supersaturadas em sílica, apresentam afinidade potássica e alto grau de evolução (mg\#<0,33, baixa concentração em $\mathrm{Cr}$ e Ni). A distribuição normalizada dos elementos incompatíveis indica anomalias negativas pronunciadas em $\mathrm{Sr}, \mathrm{P}$ e Ti e evidentes anomalias positivas em $\mathrm{Zr}$ e $\mathrm{Nd}$. O comportamento das terras raras exibe alta concentração desses elementos, fracionamento das TRL em relação às TRP e acentuada anomalia negativa em Eu. Razões iniciais ${ }^{87} \mathrm{Sr} /{ }^{86} \mathrm{Sr}\left(\mathrm{R}_{\mathrm{o}}\right)$ variam de 0,7065 a 0,70700 e de 0,7054 a 0,7078, respectivamente, para os litotipos menos e mais evoluídos. A correlação positiva entre $\mathrm{R}_{0}$ e $\mathrm{SiO}_{2}$ é evidência indicativa que essas rochas foram submetidas a processos de assimilação e contaminação crustal. A assinatura isotópica (Sr-Nd) similar à de outras ocorrências sieníticas da região sudeste do país possibilita sugerir para essas rochas uma origem a partir de magma parental basanítico, tendo sido a fonte mantélica, litosférica subcontinental e composicionalmente heterogênea, sujeita a processos de enriquecimento metassomático no Proterozóico.
\end{abstract}

Palavras-chave: magmatismo alcalino, petrologia, geoquímica, Cananéia.

\begin{abstract}
The alkaline occurrence of Cananéia, southern coast of São Paulo state: petrology and geochemistry. The Cananéia massif (Ar-Ar, 83.6 $\pm 0.9 \mathrm{Ma}$ ) in SE Brazil is represented by two small bodies - Morro de São João, $1.8 \mathrm{~km}^{2}$, and Morrete, $0.4 \mathrm{~km}^{2}$. The intrusion is covered by Quaternary sediments, has as country rocks the Açungui Group and it is tectonically associated with the Ponta Grossa Arch (Guapiara Lineament). Syenitic rocks clustered into two groups, alkali feldspar syenites and quartz-alkali feldspar syenites, are dominant and microsyenites, subordinate. Alkali feldspar (mesoperthite), quartz, clinopyroxene, amphibole and biotite are common minerals, whereas plagioclase and olivine occur rarely. Accessory phases include opaques, apatite, titanite and zircon. The Cananéia rocks are silica-saturated to oversaturated in composition, have potassic affinity and are highly evolved (mg\#<0.33, low $\mathrm{Cr}$ and $\mathrm{Ni}$ contents). The normalized distribution for the incompatible elements indicate pronounced $\mathrm{Sr}, \mathrm{P}$ and Ti negative anomalies and evident $\mathrm{Zr}$ and $\mathrm{Nd}$ positive anomalies. The earth rare elements behaviour displays high concentration, LREE to HREE fractionation and strong Eu negative spike. ${ }^{87} \mathrm{Sr} /{ }^{86} \mathrm{Sr}\left(\mathrm{R}_{\mathrm{o}}\right)$ initial ratios vary from 0.7065 to 0.70700 and from 0.7054 to 0.7078 for the less and more evolved rocks types, respectively. The positive correlation between $\mathrm{R}_{\mathrm{o}}$ and $\mathrm{SiO}_{2}$ is a clear evidence that these syenites were subjected to assimilation-crustal contamination processes. Sr-Nd isotopic signature similar to other syenitic occurrences of southern Brazil allow to suggest for these rocks an origin from a basanitic parental magma, the mantelic source, subcontinental lithospheric and heterogeneous in composition, being submitted to metassomatic enrichment processes in Proterozoic times.
\end{abstract}

Keywords: alkaline magmatism, petrology, geochemistry, Cananéia.

INTRODUÇÃO O maciço de Cananéia, no Vale do Ribeira, é um dos muitos centros alcalinos da região e tem sido objeto de investigação minuciosa nos últimos anos (Spinelli inédito, 2003, 2007; Spinelli \& Gomes 2008, 2009; Spinelli et al.2001), ainda que as primeiras notícias sobre a sua geologia e petrografia remontem a
Freitas (1947). Geomorfologicamente, ele encontra-se inserido na Planície Costeira Cananéia-Iguape (Suguio \& Tessler 1992), sendo recoberto por sedimentos quaternários arenosos de origem continental e marinha. Tem como encaixante o embasamento cristalino precambriano do Grupo Açungui (Hasui et al. 1981), representado 
na área por rochas metamórficas (filitos, mica xistos e gnaisses) recortadas por intrusões graníticas diversas.

À semelhança dos corpos alcalinos vizinhos de Jacupiranga, Juquiá e Pariquera-Açu, o de Cananéia é também controlado tectonicamente pelo Alinhamento Guapiara (Riccomini 1995), uma das feições associadas do Arco de Ponta Grossa (Almeida 1971), de orientação geral NW, e que demarca o limite norte dessa grande estrutura soerguida. Investigando mais detidamente o maciço do ponto de vista estrutural, Riccomini (1995) concluiu que ele foi submetido a duas fases distintas de deformação, uma de natureza extensional e outra de natureza transcorrente sinistral. A primeira, de direção NE-SW e idade cretácica, está ligada à extensão do Alinhamento Guapiara; a segunda, de direção NW-SE e idade paleogênica, acha-se relacionada à reativação de antigas zonas de cisalhamento do rifte continental do Sudeste Brasileiro (cf. Riccomini 1989).

A ocorrência integra a Província do Arco de Ponta Grossa (Almeida 1983), que contém numerosos centros alcalinos de idade Cretáceo Inferior e Cretáceo Superior. Mais recentemente, Ruberti et al. (2005), ao revisar o condicionamento tectônico desses corpos, distinguiram um grupo associado ao Alinhamento Guapiara, que inclui, além de Cananéia, os complexos alcalino-carbonatíticos de Jacupiranga e Juquiá e o maciço de Pariquera-Açu, e um outro ligado ao Alinhamento São Jerônimo-Curiúva. Este último engloba as intrusões de Banhadão, Barra do Itapirapuã, Itapirapuã, Mato Preto e Tunas, juntamente com plugs e diques aflorando em especial ao longo da divisa dos estados do Paraná e São Paulo.

O maciço é formado por dois pequenos corpos, Morro de São João e Morrete, localizados, respectivamen- te, nas ilhas de Cananéia e na vizinha Comprida (Fig. 1). O primeiro, maior $\left(1,8 \mathrm{~km}^{2}\right)$, aflora na área urbana da cidade de Cananéia, na forma de um pequeno morro de contorno subcircular e altitude máxima de 137 m, coberto por densa vegetação e, parcialmente, terminando na região costeira. O segundo, de menor expressão $\left(0,4 \mathrm{~km}^{2}\right.$, altitude de 47 $\mathrm{m})$, não é muito distante do anterior, porém, encontra-se separado desse último pelo Mar de Cananéia, com os estudos geofísicos conduzidos por Suguio et al. (1987) indicando a existência de uma superfície de rocha contínua (Laje do Argolão) que interliga os dois corpos.

O presente trabalho complementa os anteriores (Spinelli \& Gomes 2008, 2009), mais direcionados para a descrição geológica e petrográfica do maciço, composição química dos seus minerais e geocronologia. Com base em dados químicos e isotópicos das rochas, ele visa a contribuir para o melhor conhecimento das condições de formação e evolução petrogenética da intrusão.

PETROGRAFIA Na sua quase totalidade, a ocorrência de Cananéia é constituída por rochas de natureza sienítica, faneríticas de granulação média a grossa, cortadas esporadicamente por pequenos diques e veios de microssienito e traquito, de granulação muito fina ou mesmo afanítica. As intrusivas estão reunidas em dois grupos principais, álcali feldspato sienitos e quartzoálcali feldspato sienitos, que exibem similaridades do ponto de vista textural, com destaque para o caráter hipidiomórfico equigranular a inequigranular. Ocasionalmente, são porfiríticas, como no corpo de Morrete, ou ainda, de aspecto pegmatóide. Por sua vez, as rochas hipoabissais, em função de sua textura variada, são classificadas como microssienitos com textura em

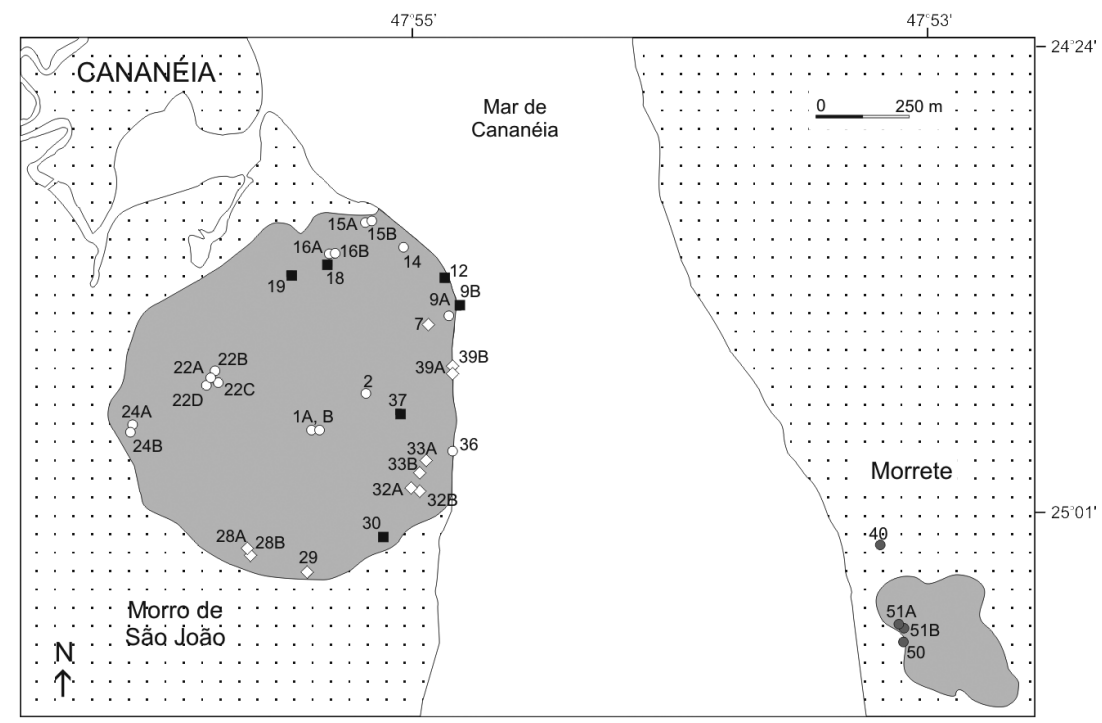

Figura 1 - Mapa de localização das amostras coletadas nos corpos alcalinos do Morro de São João e Morrete, separados pelo Mar de Cananéia, e encaixados em sedimentos quaternários (extraído e simplificado de Spinelli 2007). Símbolos: Morro de São João - losângulos vazios, álcali feldspato sienitos; círculos vazios, quartzoálcali feldspato sienitos; quadrados cheios, microssienitos; Morrete - círculos em cinza, quartzo-álcali feldspato sienitos. 
mosaico e traquítica, além de quartzo-álcali feldspato sienitos porfiríticos com matriz fina.

Mineralogicamente, feldspatos são a fase mais abundante, aparecendo de modo subordinado quartzo e constituintes máficos, em especial clinopiroxênio e anfibólio. Acidentalmente, estão presentes biotita e olivina, enquanto os acessórios mais comuns incluem apatita, minerais opacos, titanita e zircão. Feldspato alcalino é o principal mineral dessas rochas e acha-se representado por mesopertitas de textura complexa, resultantes de processos de demisturação, e típicas de suítes sieníticas. Plagioclásio, na forma de cristais isolados, ocorre raramente, sendo na maior parte das vezes de natureza sódica. Clinopiroxênio e anfibólio pertencem aos grupos cálcico, cálcico-sódico e mais raramente sódico, tendo como fases mais representativas, respectivamente, hedenbergita-augita e magnésiohornblenda-katoforita. A biotita corresponde a uma ferrobiotita e a olivina é de composição faialítica $\left(\mathrm{Fa}_{97-98}\right)$. Os minerais opacos correspondem a magnetita com lamelas exsolvidas de ilmenita, e a apatita é uma flúor-apatita com teor variável de $\mathrm{F}(1,03$ a $1,73 \%)$.

Evidências texturais demonstram que o anfibólio foi originado a partir da transformação do clinopiroxênio e que a cristalização da biotita é posterior à do anfibólio. Por outro lado, não há elementos para esclarecer o comportamento das olivina, pois os poucos grãos remanescentes do mineral nada informam a respeito de suas relações texturais. Contudo, a composição faialítica leva a supor que a sua formação tenha se dado mais tardiamente. Atividades de alteração tardimagmáticas a pós-magmáticas foram responsáveis pelas texturas de substituição presentes nos principais minerais primários, assim como pelas estruturas de exsolução encontradas nos feldspatos e opacos.

GEOQUÍMICA Os resultados químicos para amostras representativas do maciço de Cananéia estão reunidos na tabela 1. Eles demonstram que essas rochas são pobres em

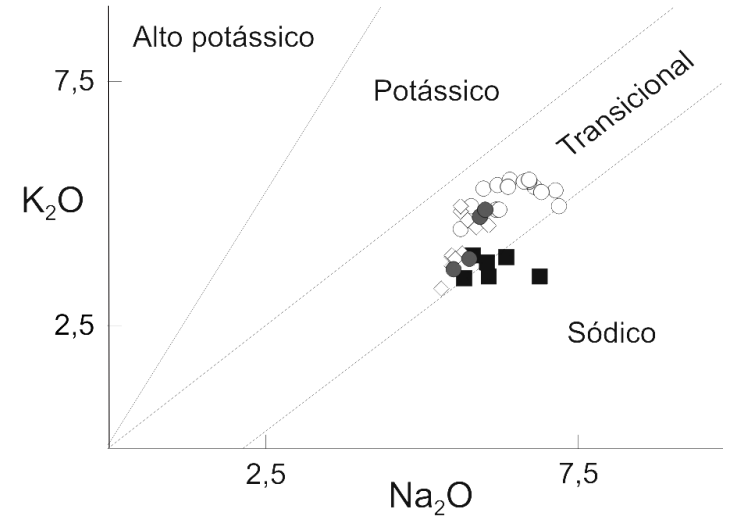

Figura 2 - Índice de alcalinidade para as rochas de Cananéia segundo os campos definidos por Comin-Chiaramonti \& Gomes (1996). Símbolos como na figura 1.

$\mathrm{Mg}, \mathrm{Mn}, \mathrm{Cr}$ e Ni, contêm altos teores em $\mathrm{Al}$ e álcalis, além de concentrações variadas em Ti, Fe e outros elementos. O exame dos dados normativos permite realçar a sua natureza saturada a supersaturada e a sua afinidade alcalina.

No esquema classificatório de Comin-Chiaramonti \& Gomes (1996), que relaciona os teores de $\mathrm{Na}_{2} \mathrm{O}$ e $\mathrm{K}_{2} \mathrm{O}$ (Fig. 2), nota-se que a quase totalidade das rochas está concentrada no campo correspondente às variedades transicionais, com apenas algumas delas situadas na zona limite com o campo das sódicas. Os valores obtidos para o índice agpaítico (I.A.) são sempre inferiores a 1, variando entre 0,74 e 1,00 (Tab. 1), o que possibilita incluí-las na série miasquítica (Sørensen 1960), como também sugerido pela sua associação mineralógica.

O diagrama classificatório R1-R2 segundo De La Roche et al. (1986) (Fig. 3) situa as amostras analisadas mormente no campo dos sienitos, com pequena incursão no campo dos quartzo sienitos, notadamente

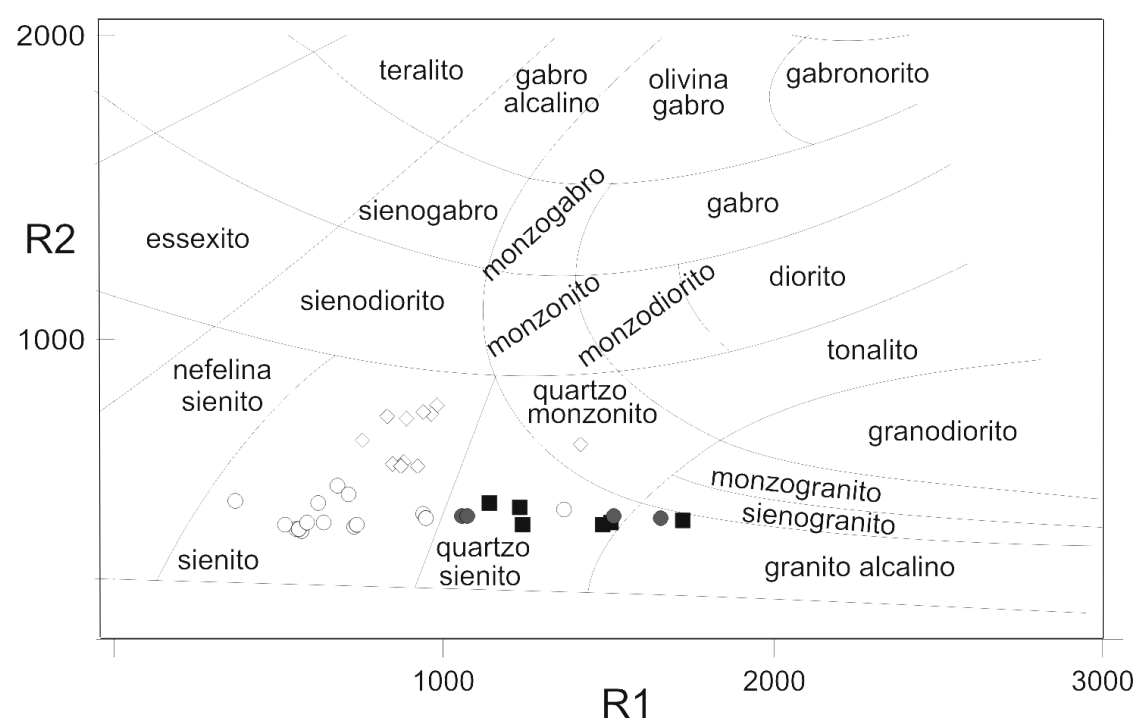

Figura 3 - Diagrama R1-R2 $[R 1=4 \mathrm{Si}-11(\mathrm{Na}+\mathrm{K})-2(\mathrm{Fe}+\mathrm{Ti})] ; \mathrm{R} 2=6 \mathrm{Ca}$ $2 \mathrm{Mg}+\mathrm{All}$ ) para as rochas de Cananéia. Símbolos como na figura 1. 
Tabela 1 - Análises químicas de elementos maiores (\%) e traços (ppm), juntamente com os valores para a norma CIPW e diagrama RI-R2 (cf. De La Roche 1986); $m g \#\left[\left(\mathrm{Mg} / \mathrm{Mg}+\mathrm{Fe}\right.\right.$ ) assumindo $\left.\mathrm{Fe}^{3+} / \mathrm{Fe}^{2+}=0,18\right]$; indice agpaítico (I.A. $=\mathrm{Na}_{2} \mathrm{O}+\mathrm{K}_{2} \mathrm{O} /$ $\mathrm{Al}_{2} \mathrm{O}_{3}$, proporção molecular, cf. Sørensen 1960); índice de cor (I.C.); índice de diferenciação (I.D. $=Q+\mathrm{Or}+\mathrm{Ab}+\mathrm{Ne}+\mathrm{Ks}+\mathrm{Lc}$, cf. Thornton \& Tuttle 1960) e razões interelementares para as rochas de Cananéia; n.d., não detectado.

\begin{tabular}{|c|c|c|c|c|c|c|c|c|c|c|c|c|c|}
\hline & 1 & 2 & 3 & 4 & 5 & 6 & 7 & 8 & 9 & 10 & 11 & 12 & 13 \\
\hline \multirow[t]{2}{*}{ Amostra } & 12 & 18 & 30 & 37 & 19 & $9 \mathrm{~B}$ & 2 & $16 \mathrm{~B}$ & $22 \mathrm{~A}$ & 36 & $9 \mathrm{~A}$ & $22 \mathrm{C}$ & $24 \mathrm{~A}$ \\
\hline & $\mathrm{Tq}$ & $\mathrm{Tq}$ & $\mathrm{Tq}$ & $\mathrm{mS}$ & $\mathrm{mS}$ & $\mathrm{Tq}$ & Qs & Qs & Qs & Qs & Qs & Qs & Qs \\
\hline $\mathrm{SiO}_{2}$ & 69,83 & 68,92 & 68,76 & 68,52 & 66,31 & 66,16 & 67,43 & 66,65 & 66,46 & 66,22 & 66,12 & 66,02 & 65,23 \\
\hline $\mathrm{TiO}_{2}$ & 0,15 & 0,09 & 0,11 & 0,17 & 0,23 & 0,23 & 0,18 & 0,21 & 0,25 & 0,33 & 0,33 & 0,09 & 0,19 \\
\hline $\mathrm{Al}_{2} \mathrm{O}_{3}$ & 16,16 & 16,56 & 16,87 & 16,2 & 17,57 & 16,78 & 17,71 & 17,8 & 17,74 & 15,91 & 15,76 & 18,24 & 17,55 \\
\hline $\mathrm{FeO}_{\mathrm{T}}$ & 3,24 & 3,16 & 2,77 & 3,56 & 3,93 & 4,99 & 2,85 & 2,1 & 2,25 & 3,66 & 4,43 & 2,26 & 3,58 \\
\hline $\mathrm{MnO}$ & 0,08 & 0,15 & 0,1 & 0,05 & 0,12 & 0,18 & 0,1 & 0,03 & 0,03 & 0,08 & 0,16 & 0,04 & 0,03 \\
\hline $\mathrm{MgO}$ & n.d. & n.d. & n.d. & n.d. & 0,06 & 0,06 & 0,1 & 0,01 & 0,03 & 0,13 & 0,18 & n.d. & 0,04 \\
\hline $\mathrm{CaO}$ & 0,76 & 0,57 & 0,46 & 0,59 & 0,97 & 0,98 & 0,76 & 0,26 & 0,28 & 0,81 & 0,91 & 0,05 & 0,38 \\
\hline $\mathrm{Na}_{2} \mathrm{O}$ & 5,68 & 5,81 & 6,86 & 6,05 & 6,34 & 6,02 & 5,61 & 6,69 & 6,61 & 6,23 & 6,18 & 7,11 & 6,7 \\
\hline $\mathrm{K}_{2} \mathrm{O}$ & 3,48 & 3,95 & 3,51 & 3,53 & 3,9 & 3,8 & 4,47 & 5,45 & 5,46 & 4,89 & 4,89 & 5,28 & 5,47 \\
\hline $\overrightarrow{\mathrm{P}_{2} \mathrm{O}_{5}}$ & n.d. & n.d. & n.d. & n.d. & 0,03 & 0,02 & 0,01 & 0,01 & 0,01 & 0,07 & 0,07 & 0,01 & 0,01 \\
\hline P.F. & 0,61 & 0,79 & 0,58 & 1,33 & 0,54 & 0,77 & 0,79 & 0,81 & 0,88 & 0,37 & 0,51 & 0,89 & 0,82 \\
\hline Total & 99,99 & 100 & 100,02 & 100 & 100 & 99,99 & 100,01 & 100,02 & 100 & 98,7 & 99,54 & 99,99 & 100 \\
\hline $\mathrm{Cr}$ & 6,7 & 4 & 26,18 & 1 & 16,1 & 5 & 0 & 1 & 2 & 10 & 10,35 & 0 & 2 \\
\hline $\mathrm{Ni}$ & 7,65 & 0 & 14,01 & 5 & 12,01 & 4 & 2 & 2 & 3 & 10 & 10,84 & 7 & 3 \\
\hline $\mathrm{Rb}$ & 126,53 & 146 & 71,83 & 117 & 113,28 & 101 & 109 & 138 & 141 & 126 & 131 & 156 & 97 \\
\hline $\mathrm{Sr}$ & 703,58 & 9 & 358,87 & 14 & 257,2 & 16 & 29 & 13 & 13 & 69 & 76 & 13 & 10 \\
\hline $\mathrm{Zr}$ & 1048 & 698 & 866 & 1037 & 851 & 784 & 726 & 766 & 730 & 692 & 727 & 540 & 181 \\
\hline $\mathrm{Y}$ & 89 & 71 & 89 & 110 & 52 & 65 & 29 & 66 & 73 & 76 & 79 & 47 & 34 \\
\hline $\mathrm{Nb}$ & 91,08 & 120 & 44,75 & 119 & 79,88 & 102 & 32 & 122 & 138 & 49 & 59 & 66 & 34 \\
\hline $\mathrm{Ba}$ & 89 & 66 & 43 & 77 & 306 & 203 & 315 & 138 & 141 & 552,9 & 503,1 & 176 & 289 \\
\hline $\mathrm{La}$ & 118,65 & 114 & 43,36 & 194 & 84,3 & 146 & 54 & 120 & 136 & 173,11 & 135,59 & 121 & 63 \\
\hline $\mathrm{Ce}$ & 224,37 & 201 & 82 & 326 & 167,21 & 258 & 95 & 216 & 239 & 281,57 & 245,47 & 151 & 62 \\
\hline $\mathrm{Nd}$ & 193,76 & 95 & 49,79 & 143 & 113,44 & 120 & 45 & 81 & 92 & 102,87 & 86,14 & 74 & 45 \\
\hline $\mathrm{Sm}$ & 18,26 & & 9,01 & & 14,55 & & & & & 8,69 & 16,02 & & \\
\hline $\mathrm{Eu}$ & 2,03 & & 2,79 & & 1,64 & & & & & 2 & 2,04 & & \\
\hline $\mathrm{Gd}$ & 19,95 & & 10,1 & & 15,09 & & & & & 5,98 & 13,24 & & \\
\hline $\mathrm{Tb}$ & 3,18 & & 1,5 & & 2,18 & & & & & 0,83 & 2,39 & & \\
\hline Dy & 18,97 & & 6,71 & & 11,93 & & & & & 3,9 & 11,64 & & \\
\hline Ho & 3,42 & & 1,69 & & 2,27 & & & & & 0,63 & 2,56 & & \\
\hline Er & 9,92 & & 3,82 & & 5,84 & & & & & 1,84 & 6,53 & & \\
\hline $\mathrm{Tm}$ & 2,09 & & 0,79 & & 1,16 & & & & & 0,33 & 1,27 & & \\
\hline $\mathrm{Yb}$ & 10,7 & & 3,76 & & 6,12 & & & & & 2 & 5,87 & & \\
\hline $\mathrm{Lu}$ & 1,49 & & 0,5 & & 0,99 & & & & & 0,3 & 1,17 & & \\
\hline $\mathrm{Pb}$ & 32,55 & & 171,47 & & 324,81 & & & & & & & & \\
\hline Th & 30,35 & & 7,46 & & 11,55 & & & & & 11,47 & 13,44 & & \\
\hline $\mathrm{U}$ & 7,85 & & 2,19 & & 2,85 & & & & & 1,65 & 1,73 & & \\
\hline $\mathrm{Sc}$ & 1,7 & & 11,33 & & 3,72 & & & & & & & & \\
\hline $\mathrm{V}$ & 11,65 & & 56,64 & & 24,47 & & & & & 8,96 & 8,11 & & \\
\hline $\mathrm{Co}$ & 1,7 & & 8,5 & & 5,01 & & & & & & & & \\
\hline $\mathrm{Cu}$ & 28,26 & & 72,08 & & 152,5 & & & & & 50,09 & 32,44 & & \\
\hline $\mathrm{Zn}$ & 40,27 & & 179,92 & & 1043,7 & & & & & 121,24 & 227,34 & & \\
\hline $\mathrm{Pr}$ & 22,51 & & 9,82 & & 18,38 & & & & & 19,68 & 25,39 & & \\
\hline $\mathrm{Q}$ & 19,87 & 16,78 & 12,68 & 16,5 & 9,95 & 11,28 & 14,22 & 5,12 & 5,22 & 7,98 & 7,4 & 2,94 & 2,28 \\
\hline $\mathrm{C}$ & 1,67 & 1,7 & 0,95 & 1,37 & 1,23 & 1,03 & 2,3 & 0,44 & 0,47 & - & - & 0,76 & - \\
\hline or & 20,68 & 23,52 & 20,85 & 21,13 & 23,16 & 22,62 & 26,61 & 32,46 & 32,54 & 29,37 & 29,16 & 31,48 & 32,58 \\
\hline$a b$ & 48,34 & 49,53 & 58,35 & 51,86 & 53,91 & 51,3 & 47,83 & 57,05 & 56,41 & 53,58 & 52,77 & 60,69 & 57,13 \\
\hline an & 3,79 & 2,85 & 2,29 & 2,97 & 4,64 & 4,77 & 3,73 & 1,23 & 1,34 & 1 & 0,81 & 0,18 & 1,65 \\
\hline ne & - & - & - & - & - & - & - & - & - & - & - & - & - \\
\hline di (Wo) & - & - & - & - & - & - & - & - & - & 1,09 & 1,37 & - & 0,08 \\
\hline di (En) & - & - & - & - & - & - & - & - & - & 0,08 & 0,1 & - & 0 \\
\hline $\mathrm{di}(\mathrm{Fs})$ & - & - & - & - & - & - & - & - & - & 1,14 & 1,42 & - & 0,08 \\
\hline hi (En) & - & - & - & - & 0,15 & 0,15 & 0,25 & 0,02 & 0,08 & 0,25 & 0,35 & - & 0,1 \\
\hline hi (Fs) & 4,62 & 4,71 & 4,02 & 5,05 & 5,55 & 7,21 & 4,03 & 2,78 & 2,93 & 3,85 & 4,78 & 3,23 & 4,9 \\
\hline
\end{tabular}


Tabela 1 - Continuação

\begin{tabular}{l|c|c|c|c|c|c|c|c|c|c|c|c|c}
\hline $\mathrm{ol}(\mathrm{Fo})$ & - & - & - & - & - & - & - & - & - & - & - & - & - \\
\hline $\mathrm{ol}(\mathrm{Fa})$ & - & - & - & - & - & - & - & - & - & - & - & - & - \\
\hline $\mathrm{mt}$ & 0,73 & 0,72 & 0,63 & 0,8 & 0,89 & 1,14 & 0,64 & 0,46 & 0,5 & 0,83 & 1,01 & 0,5 & 0,79 \\
\hline $\mathrm{ilm}$ & 0,29 & 0,17 & 0,21 & 0,33 & 0,44 & 0,44 & 0,34 & 0,4 & 0,48 & 0,64 & 0,63 & 0,17 & 0,36 \\
\hline $\mathrm{ap}$ & - & - & - & - & 0,07 & 0,04 & 0,02 & 0,02 & 0,02 & 0,16 & 0,15 & 0,02 & 0,02 \\
\hline & & & & & & & & & & & & & \\
\hline $\mathrm{R} 1$ & 1726 & 1513 & 1243 & 1486 & 1138 & 1241 & 1370 & 726 & 734 & 945 & 939 & 578 & 587 \\
\hline $\mathrm{R} 2$ & 398 & 386 & 380 & 381 & 451 & 437 & 434 & 377 & 379 & 405 & 416 & 363 & 387 \\
\hline $\mathrm{mg} \#$ & 0 & 0 & 0 & 0 & 0,03 & 0,02 & 0,07 & 0,01 & 0,03 & 0,07 & 0,08 & 0 & 0,02 \\
\hline $\mathrm{I} . \mathrm{A}$. & 0,81 & 0,84 & 0,89 & 0,85 & 0,83 & 0,84 & 0,79 & 0,95 & 0,95 & 0,98 & 0,98 & 0,95 & 0,97 \\
\hline $\mathrm{I} . \mathrm{C}$. & 5,63 & 5,61 & 4,86 & 6,17 & 7,03 & 8,96 & 5,27 & 3,67 & 3,98 & 7,87 & 9,67 & 3,9 & 6,34 \\
\hline $\mathrm{I} . \mathrm{D}$. & 88,89 & 89,83 & 91,89 & 89,49 & 87,02 & 85,16 & 88,66 & 94,62 & 94,17 & 90,93 & 89,33 & 95,11 & 92,02 \\
\hline & & & & & & & & & & & & & \\
\hline $\mathrm{Eu} / \mathrm{Eu} *$ & 0,32 & & 0,89 & & 0,34 & & & & & 0,85 & 0,43 & & \\
\hline$(\mathrm{La} / \mathrm{Sm})_{\mathrm{N}}$ & 4,06 & & 3 & & 3,62 & & & & & 12,44 & 9,57 & & \\
\hline$(\mathrm{Gd} / \mathrm{Yb})_{\mathrm{N}}$ & 1,51 & & 2,18 & & 1,99 & & & & & 2,42 & 1,82 & & \\
\hline$(\mathrm{La} / \mathrm{Yb})_{\mathrm{N}}$ & 7,53 & & 7,84 & & 9,36 & & & & & 58,8 & 28,41 & & \\
\hline
\end{tabular}

\begin{tabular}{|c|c|c|c|c|c|c|c|c|c|c|c|c|}
\hline & 14 & 15 & 16 & 17 & 18 & 19 & 20 & 21 & 22 & 23 & 24 & 25 \\
\hline Amostra & $22 \mathrm{D}$ & $22 \mathrm{~B}$ & $16 \mathrm{~A}$ & $15 \mathrm{~B}$ & $1 \mathrm{~B}$ & $24 \mathrm{~B}$ & 14 & $39 \mathrm{~B}$ & $33 \mathrm{~B}$ & $1 \mathrm{~A}$ & $33 \mathrm{~A}$ & $39 \mathrm{~A}$ \\
\hline & Qs & Qs & Qs & Qs & Qs & Qs & Qs & As & As & Qs & As & As \\
\hline $\mathrm{SiO}_{2}$ & 65 & 64,9 & 64,75 & 64,55 & 64,5 & 64,42 & 63,71 & 63,59 & 63,46 & 63,21 & 62,77 & 62,45 \\
\hline $\mathrm{TiO}_{2}$ & 0,15 & 0,13 & 0,14 & 0,26 & 0,37 & 0,28 & 0,71 & 0,43 & 0,65 & 0,49 & 0,67 & 0,69 \\
\hline $\mathrm{Al}_{2} \mathrm{O}_{3}$ & 17,93 & 17,55 & 17,47 & 16,96 & 17,16 & 16,91 & 16,48 & 17,1 & 16,6 & 16,26 & 16,42 & 19,37 \\
\hline $\mathrm{FeO}_{\mathrm{T}}$ & 3,52 & 3,44 & 3,71 & 4,14 & 4,07 & 5,07 & 5,79 & 5,1 & 5,07 & 5,68 & 5,68 & 6,29 \\
\hline $\mathrm{MnO}$ & 0,07 & 0,13 & 0,12 & 0,22 & 0,1 & 0,07 & 0,14 & 0,18 & 0,1 & 0,19 & 0,16 & 0,22 \\
\hline $\mathrm{MgO}$ & 0,04 & 0,03 & 0,05 & 0,11 & 0,3 & 0,06 & 1,28 & 0,36 & 0,9 & 0,52 & 0,9 & 0,5 \\
\hline $\mathrm{CaO}$ & 0,13 & 0,33 & 0,19 & 1,08 & 1,2 & 0,5 & 2,45 & 2,05 & 1,94 & 1,53 & 2,1 & 2,22 \\
\hline $\mathrm{Na}_{2} \mathrm{O}$ & 6,89 & 7,18 & 6,78 & 6,4 & 6,21 & 6,36 & 5,31 & 6,05 & 5,61 & 5,97 & 5,61 & 5,73 \\
\hline $\mathrm{K}_{2} \mathrm{O}$ & 5,23 & 4,95 & 5,33 & 5,5 & 5,37 & 5,35 & 3,27 & 4,55 & 4,95 & 5,31 & 4,85 & 4,66 \\
\hline $\mathrm{P}_{2} \mathrm{O}_{5}$ & 0,02 & 0,01 & 0,02 & 0,03 & 0,06 & 0,03 & 0,14 & 0,12 & 0,15 & 0,07 & 0,13 & 0,17 \\
\hline P.F. & 1,01 & 1,33 & 1,44 & 0,76 & 0,66 & 0,95 & 0,71 & 0,49 & 0,58 & 0,78 & 0,69 & 0,71 \\
\hline Total & 99,99 & 99,98 & 100 & 100,01 & 100 & 100 & 99,99 & 100,02 & 100,01 & 100,01 & 99,98 & 103,01 \\
\hline $\mathrm{Cr}$ & 0 & 13,3 & 3 & 7,58 & 11,28 & 0 & 7 & 12,93 & 7 & 5 & 4 & 10 \\
\hline $\mathrm{Ni}$ & 6 & 12,04 & 2 & 6,66 & 6,48 & 5 & 5 & 16,53 & 5 & 1 & 9 & 9 \\
\hline $\mathrm{Rb}$ & 150 & 170,25 & 170 & 100,94 & 116,82 & 133 & 100 & 78,58 & 115 & 114 & 115 & 72 \\
\hline $\mathrm{Sr}$ & 14 & 395,28 & 25 & 388,16 & 208,79 & 10 & 165 & 297,13 & 124 & 58 & 144 & 156 \\
\hline $\mathrm{Zr}$ & 577 & 717 & 708 & 210 & 1343 & 557 & 383 & 207 & 504 & 1165 & 472 & 330 \\
\hline $\mathrm{Y}$ & 59 & 77 & 69 & 28 & 193 & 62 & 38 & 26 & 39 & 79 & 53 & 42 \\
\hline $\mathrm{Nb}$ & 67 & 91,94 & 96 & 34,34 & 114,78 & 92 & 52 & 27,76 & 42 & 77 & 65 & 56 \\
\hline $\mathrm{Ba}$ & 202 & 198 & 268 & 59 & 637 & 263 & 1155 & 2242 & 1179 & 666 & 1310 & 1995 \\
\hline $\mathrm{La}$ & 207 & 133,17 & 169 & 31,27 & 162,93 & 162 & 54 & 21,5 & 45 & 120 & 46 & 39 \\
\hline $\mathrm{Ce}$ & 358 & 237,7 & 270 & 60,22 & 254,63 & 215 & 105 & 44,73 & 78 & 194 & 92 & 68 \\
\hline $\mathrm{Nd}$ & 133 & 132,57 & 103 & 34,75 & 97,34 & 120 & 53 & 39,19 & 33 & 70 & 45 & 31 \\
\hline $\mathrm{Sm}$ & & 16,22 & & 6,66 & 21,79 & & & 5,81 & & & & \\
\hline $\mathrm{Eu}$ & & 1 & & 1,03 & 2,73 & & & 0,72 & & & & \\
\hline $\mathrm{Gd}$ & & 14,77 & & 8,3 & 26,15 & & & 7,25 & & & & \\
\hline $\mathrm{Tb}$ & & 2,33 & & 1,12 & 4,16 & & & 1,1 & & & & \\
\hline Dy & & 10,18 & & 4,49 & 21,87 & & & 4,52 & & & & \\
\hline Ho & & 2,36 & & 0,68 & 5,3 & & & 1,28 & & & & \\
\hline $\mathrm{Er}$ & & 5,32 & & 2,3 & 13,72 & & & 2,34 & & & & \\
\hline $\mathrm{Tm}$ & & 0,96 & & 0,47 & 2,92 & & & 0,51 & & & & \\
\hline $\mathrm{Yb}$ & & 4,85 & & 2,79 & 14,02 & & & 2,77 & & & & \\
\hline $\mathrm{Lu}$ & & 0,63 & & 0,5 & 2,19 & & & 0,39 & & & & \\
\hline $\mathrm{Pb}$ & & 270,22 & & 67,1 & 125,89 & & & 129,96 & & & & \\
\hline Th & & 16,74 & & 4,71 & 13,81 & & & 5,97 & & & & \\
\hline $\mathrm{U}$ & & 5,23 & & 3,22 & 3,86 & & & 1,63 & & & & \\
\hline $\mathrm{Sc}$ & & 1,73 & & 4,07 & 4,98 & & & 7,81 & & & & \\
\hline $\mathrm{V}$ & & 18,67 & & 18 & 17,03 & & & 25,58 & & & & \\
\hline Co & & 1,25 & & 2,12 & 2,05 & & & 1,62 & & & & \\
\hline
\end{tabular}


Tabela 1 - Continuação

\begin{tabular}{|c|c|c|c|c|c|c|c|c|c|c|c|c|}
\hline $\mathrm{Cu}$ & & 46,3 & & 8,45 & 8,66 & & & 60,93 & & & & \\
\hline $\mathrm{Zn}$ & & 299,19 & & 205,27 & 133,23 & & & 50,81 & & & & \\
\hline $\operatorname{Pr}$ & & 23,71 & & 7,5 & 27,01 & & & 5,78 & & & & \\
\hline Q & 2,37 & 1,33 & 2,08 & 2,03 & 3,04 & 2,8 & 10,2 & 3,95 & 4,57 & 1,92 & 3,67 & 3,5 \\
\hline C & 0,75 & - & 0,25 & - & - & - & 0,08 & - & - & - & - & - \\
\hline or & 31,21 & 29,64 & 31,94 & 32,73 & 31,93 & 31,9 & 19,45 & 27 & 29,4 & 31,6 & 28,84 & 27,71 \\
\hline$a b$ & 58,87 & 61,56 & 58,18 & 54,53 & 52,87 & 54,29 & 45,22 & 51,4 & 47,71 & 50,87 & 47,77 & 48,78 \\
\hline an & 0,52 & 1,03 & 0,82 & 1,3 & 3,09 & 1,79 & 11,31 & 6,07 & 5,5 & 1,88 & 5,31 & 5,2 \\
\hline ne & - & - & - & - & - & - & - & - & - & - & - & - \\
\hline di (Wo) & - & 0,23 & - & 1,63 & 1,05 & 0,21 & - & 1,4 & 1,33 & 2,21 & 1,8 & 1,99 \\
\hline di (En) & - & 0 & - & 0,08 & 0,14 & 0,01 & - & 0,17 & 0,36 & 0,34 & 0,44 & 0,28 \\
\hline di (Fs) & - & 0,26 & - & 1,75 & 1,01 & 0,24 & - & 1,36 & 1,04 & 2,06 & 1,47 & 1,89 \\
\hline hi (En) & 0,1 & 0,07 & 0,13 & 0,19 & 0,61 & 0,15 & 3,2 & 0,72 & 1,89 & 0,96 & 1,81 & 0,97 \\
\hline hi (Fs) & 5,04 & 4,8 & 5,43 & 4,23 & 4,5 & 6,86 & 7,53 & 5,66 & 5,46 & 5,75 & 5,99 & 6,52 \\
\hline ol (Fo) & - & - & - & - & - & - & - & - & - & - & - & - \\
\hline ol (Fa) & - & - & - & - & - & - & - & - & - & - & - & - \\
\hline $\mathrm{mt}$ & 0,79 & 0,79 & 0,85 & 0,96 & 0,91 & 1,13 & 1,3 & 1,16 & 1,13 & 1,29 & 1,28 & 1,43 \\
\hline ilm & 0,29 & 0,25 & 0,27 & 0,5 & 0,71 & 0,54 & 1,36 & 0,82 & 1,24 & 0,94 & 1,28 & 1,32 \\
\hline ap & 0,04 & 0,02 & 0,04 & 0,07 & 0,13 & 0,07 & 0,31 & 0,26 & 0,33 & 0,15 & 0,29 & 0,37 \\
\hline R1 & 563 & 522 & 557 & 624 & 717 & 638 & 1419 & 875 & 924 & 683 & 884 & 847 \\
\hline R2 & 367 & 381 & 365 & 454 & 480 & 388 & 650 & 573 & 578 & 509 & 592 & 643 \\
\hline $\mathrm{mg} \#$ & 0,02 & 0,02 & 0,03 & 0,05 & 0,13 & 0,02 & 0,31 & 0,13 & 0,27 & 0,16 & 0,25 & 0,14 \\
\hline I.A. & 0,95 & 0,98 & 0,97 & 0,97 & 0,93 & 0,96 & 0,74 & 0,87 & 0,88 & 0,96 & 0,88 & 0,75 \\
\hline I.C. & 6,22 & 6,45 & 6,69 & 9,45 & 9,11 & 9,23 & 13,74 & 11,68 & 12,91 & 13,8 & 14,48 & 14,93 \\
\hline I.D. & 92,44 & 92,54 & 92,18 & 89,28 & 87,82 & 89,01 & 74,73 & 82,28 & 81,6 & 84,35 & 80,21 & 79,88 \\
\hline $\mathrm{Eu} / \mathrm{Eu}^{*}$ & & 0,2 & & 0,42 & 0,35 & & & 0,34 & & & & \\
\hline$(\mathrm{La} / \mathrm{Sm})_{\mathrm{N}}$ & & 5,13 & & 2,93 & 4,67 & & & 2,31 & & & & \\
\hline$(\mathrm{Gd} / \mathrm{Yb})_{\mathrm{N}}$ & & 2,46 & & 2,4 & 1,51 & & & 2,12 & & & & \\
\hline$(\mathrm{La} / \mathrm{Yb})_{\mathrm{N}}$ & & 18,64 & & 7,61 & 7,9 & & & 5,27 & & & & \\
\hline & & & & & & & & & & & & \\
\hline & & 27 & 28 & 29 & 30 & 31 & 32 & 33 & 34 & 35 & 36 & \\
\hline Amostra & & $32 \mathrm{~A}$ & $28 \mathrm{~B}$ & $32 \mathrm{~B}$ & $28 \mathrm{~A}$ & $15 \mathrm{~A}$ & 29 & 40 & 50 & $51 \mathrm{~B}$ & $51 \mathrm{~A}$ & \\
\hline & & As & As & As & As & Qs & As & Qs & Qs & Qs & Qs & \\
\hline $\mathrm{SiO}_{2}$ & & 60,71 & 60,55 & 60,54 & 60,25 & 59,07 & 58,98 & 68,73 & 68,54 & 67,04 & 66,22 & \\
\hline $\mathrm{TiO}_{2}$ & & 0,92 & 0,92 & 0,96 & 0,93 & 0,32 & 0,08 & 0,28 & 0,3 & 0,29 & 0,33 & \\
\hline $\mathrm{Al}_{2} \mathrm{O}_{3}$ & & 16,41 & 16,5 & 16,39 & 16,41 & 14,91 & 16,8 & 16,6 & 16,73 & 15,91 & 16,09 & \\
\hline $\mathrm{FeO}_{\mathrm{T}}$ & & 6,83 & 6,8 & 7,01 & 6,95 & 12,61 & 7,32 & 3,64 & 3,45 & 4,14 & 4,78 & \\
\hline $\mathrm{MnO}$ & & 0,16 & 0,15 & 0,16 & 0,15 & 0,47 & 0,15 & 0,09 & 0,08 & 0,08 & 0,08 & \\
\hline $\mathrm{MgO}$ & & 1,54 & 1,47 & 1,56 & 1,55 & 0,23 & 1,72 & 0,17 & 0,15 & 0,15 & 0,21 & \\
\hline $\mathrm{CaO}$ & & 3,11 & 3,26 & 3,33 & 3,54 & 1,45 & 3,06 & 0,64 & 0,71 & 0,82 & 0,78 & \\
\hline $\mathrm{Na}_{2} \mathrm{O}$ & & 5,65 & 5,48 & 5,54 & 5,46 & 5,77 & 5,46 & 5,51 & 5,76 & 6 & 5,92 & \\
\hline $\mathrm{K}_{2} \mathrm{O}$ & & 3,99 & 3,91 & 3,87 & 3,74 & 4,96 & 3,96 & 3,65 & 3,86 & 4,88 & 4,74 & \\
\hline $\mathrm{P}_{2} \mathrm{O}_{5}$ & & 0,24 & 0,2 & 0,24 & 0,24 & 0,09 & 0,29 & 0,04 & 0,04 & 0,05 & 0,07 & \\
\hline P.F. & & 0,45 & 0,75 & 0,4 & 0,78 & 0,11 & 0,38 & 0,67 & 0,38 & 0,63 & 0,78 & \\
\hline Total & & 100,01 & 99,99 & 100 & 100 & 99,99 & 98,2 & 100,02 & 100 & 99,99 & 100 & \\
\hline & & & & & & & & & & & & \\
\hline $\mathrm{Cr}$ & & 16 & 8 & 15,86 & 6,38 & 9,42 & 12,93 & 3 & 2 & 5 & 8 & \\
\hline $\mathrm{Ni}$ & & 10 & 13 & 12,02 & 5,36 & 27,17 & 16,53 & 6 & 1 & 4 & 3 & \\
\hline $\mathrm{Rb}$ & & 104 & 87 & 88,03 & 235,52 & 111,55 & 78,58 & 120 & 124 & 149 & 140 & \\
\hline $\mathrm{Sr}$ & & 222 & 245 & 309,18 & 202,13 & 173,95 & 297,13 & 74 & 73 & 83 & 89 & \\
\hline $\mathrm{Zr}$ & & 581 & 358 & 337 & 322 & 269 & 291 & 627 & 756 & 912 & 820 & \\
\hline $\mathrm{Y}$ & & 73 & 147 & 53 & 46 & 39 & 42 & 62 & 56 & 76 & 83 & \\
\hline $\mathrm{Nb}$ & & 70 & 45 & 43,63 & 88,4 & 51,8 & 27,76 & 77 & 87 & 100 & 96 & \\
\hline $\mathrm{Ba}$ & & 1334 & 1461 & 1429 & 1434 & 64 & 474,3 & 1019 & 825 & 897 & 980 & \\
\hline $\mathrm{La}$ & & 59 & 63 & 47,35 & 95,37 & 44,83 & 21,5 & 168 & 114 & 119 & 132 & \\
\hline $\mathrm{Ce}$ & & 94 & 87 & 82,84 & 170,69 & 90,94 & 44,73 & 256 & 206 & 214 & 203 & \\
\hline $\mathrm{Nd}$ & & 45 & 46 & 71,16 & 185,87 & 56,66 & 39,19 & 144 & 99 & 92 & 106 & \\
\hline
\end{tabular}


Tabela 1 - Continuação

\begin{tabular}{|c|c|c|c|c|c|c|c|c|c|c|c|}
\hline $\mathrm{Sm}$ & & & 8,95 & 16,77 & 9,47 & 8,48 & & & & & \\
\hline $\mathrm{Eu}$ & & & 2,87 & 2,41 & 1,86 & 2,03 & & & & & \\
\hline $\mathrm{Gd}$ & & & 10,77 & 16,64 & 9,71 & 7,43 & & & & & \\
\hline $\mathrm{Tb}$ & & & 1,74 & 2,83 & 1,52 & 1,18 & & & & & \\
\hline Dy & & & 8,94 & 14,52 & 4,43 & 6,28 & & & & & \\
\hline Ho & & & 1,56 & 2,84 & 1,37 & 1,25 & & & & & \\
\hline Er & & & 4,72 & 8,6 & 3,47 & 3,38 & & & & & \\
\hline $\mathrm{Tm}$ & & & 0,98 & 1,79 & 0,84 & 0,5 & & & & & \\
\hline $\mathrm{Yb}$ & & & 4,86 & 9,36 & 4,97 & 2,92 & & & & & \\
\hline $\mathrm{Lu}$ & & & 0,61 & 1,36 & 0,8 & 0,67 & & & & & \\
\hline $\mathrm{Pb}$ & & & 115,32 & 122,4 & 84,97 & & & & & & \\
\hline $\mathrm{Th}$ & & & 9,99 & 18,55 & 6,13 & 7,57 & & & & & \\
\hline $\mathrm{U}$ & & & 2,41 & 5,24 & 43 & 0,85 & & & & & \\
\hline $\mathrm{Sc}$ & & & 9,67 & 1,34 & 4,73 & & & & & & \\
\hline $\mathrm{V}$ & & & 50,27 & 18,05 & 21,34 & 69,99 & & & & & \\
\hline Co & & & 7,36 & 5,47 & 0,69 & & & & & & \\
\hline $\mathrm{Cu}$ & & & 30,54 & 42,66 & 86,52 & 77,15 & & & & & \\
\hline $\mathrm{Zn}$ & & & 83,02 & 140,29 & 137,02 & 186,86 & & & & & \\
\hline $\operatorname{Pr}$ & & & 10,34 & 21,39 & 11,38 & 11,83 & & & & & \\
\hline & & & & & & & & & & & \\
\hline $\mathrm{Q}$ & 1,69 & 2,48 & 2,1 & 2,42 & - & 0,41 & 19,05 & 16,57 & 9,46 & 8,96 & \\
\hline $\mathrm{C}$ & - & - & - & - & - & - & 2,53 & 1,88 & - & - & \\
\hline or & 23,66 & 23,26 & 22,94 & 22,25 & 29,29 & 23,66 & 21,7 & 22,89 & 29,01 & 28,21 & \\
\hline$a b$ & 47,97 & 46,68 & 47,02 & 46,52 & 44,7 & 46,7 & 46,91 & 48,9 & 51,07 & 50,45 & \\
\hline an & 7,64 & 8,92 & 8,43 & 9,27 & 0,12 & 9,72 & 2,93 & 3,27 & 2,06 & 3,34 & \\
\hline ne & - & - & - & - & 2,21 & - & - & - & - & - & \\
\hline di (Wo) & 2,61 & 2,52 & 2,74 & 2,85 & 2,7 & 1,55 & - & - & 0,71 & 0,04 & \\
\hline di (En) & 0,83 & 0,78 & 0,86 & 0,9 & 0,09 & 0,51 & - & - & 0,05 & 0 & \\
\hline di (Fs) & 1,88 & 1,84 & 1,98 & 2,06 & 2,96 & 1,09 & - & - & 0,74 & 0,04 & \\
\hline hi (En) & 3 & 2,89 & 3,02 & 2,97 & - & 3,8 & 0,42 & 0,37 & 0,33 & 0,52 & \\
\hline hi (Fs) & 6,83 & 6,84 & 6,92 & 6,82 & - & 8,13 & 5,01 & 4,67 & 4,97 & 6,55 & \\
\hline ol (Fo) & - & - & - & - & 0,34 & - & - & - & - & - & \\
\hline $\mathrm{ol}(\mathrm{Fa})$ & - & - & - & - & 12,05 & - & - & - & - & - & \\
\hline $\mathrm{mt}$ & 1,54 & 1,53 & 1,57 & 1,56 & 2,87 & 1,65 & 0,82 & 0,77 & 0,92 & 1,07 & \\
\hline $\mathrm{ilm}$ & 1,75 & 1,76 & 1,83 & 1,78 & 0,61 & 2,07 & 0,54 & 0,57 & 0,55 & 0,63 & \\
\hline ap & 0,53 & 0,44 & 0,53 & 0,53 & 0,2 & 0,64 & 0,09 & 0,09 & 0,11 & 0,15 & \\
\hline & & & & & & & & & & & \\
\hline $\mathrm{R} 1$ & 896 & 965 & 946 & 988 & 371 & 862 & 1659 & 1513 & 1071 & 1058 & \\
\hline $\mathrm{R} 2$ & 732 & 746 & 756 & 779 & 459 & 743 & 403 & 412 & 407 & 409 & \\
\hline $\mathrm{mg} \#$ & 0,32 & 0,31 & 0,32 & 0,32 & 0,04 & 0,33 & 0,09 & 0,08 & 0,07 & 0,08 & \\
\hline I.A. & 0,83 & 0,8 & 0,81 & 0,79 & 1 & 0,79 & 0,78 & 0,82 & 0,95 & 0,92 & \\
\hline I.C. & 19,21 & 18,8 & 19,68 & 19,71 & 21,97 & 18,8 & 6,78 & 6,38 & 8,27 & 9,06 & \\
\hline I.D. & 73,17 & 72,28 & 71,89 & 71,02 & 77,94 & 70,77 & 87,65 & 88,36 & 89,53 & 87,61 & \\
\hline $\mathrm{Eu} / \mathrm{Eu}^{*}$ & & & 0,89 & 0,44 & 0,59 & 078 & & & & & \\
\hline$(\mathrm{La} / \mathrm{Sm})_{\mathrm{N}}$ & & & 3,3 & 3,55 & 2,96 & 1,58 & & & & & \\
\hline$(\mathrm{Gd} / \mathrm{Yb})_{\mathrm{N}}$ & & & 1,8 & 1,44 & 1,58 & 2,06 & & & & & \\
\hline$(\mathrm{La} / \mathrm{Yb})_{\mathrm{N}}$ & & & 6,62 & 6,92 & 6,13 & 5 & & & & & \\
\hline
\end{tabular}

para as variedades hipoabissais. Quando projetadas no diagrama TAS de Le Maitre (2003) (não apresentado), elas ocupam os campos dos traquitos e traquiandesitos, evidenciando, a exemplo do gráfico anterior, a sua natureza fortemente alcalina e riqueza em sílica.

As análises químicas indicam também o alto grau de evolução dessas rochas, com os valores para o índice de diferenciação compreendidos no intervalo de $72-95 \%$. Esse caráter evoluído é ainda demonstrado pelos valores muito baixos da razão $\mathrm{Mg} / \mathrm{Mg}+\mathrm{Fe}$ (mg\# infe- rior a 0,33 ) e pelas baixas concentrações de $\mathrm{Cr}$ e Ni. As variações químicas presentes nos elementos maiores e traços são mostradas nos diagramas de Harker. No geral, as rochas de Cananéia apresentam correlações positivas para $\mathrm{Al}_{2} \mathrm{O}_{3}, \mathrm{Na}_{2} \mathrm{O}$ e $\mathrm{K}_{2} \mathrm{O}$ em relação à proporção de $\mathrm{SiO}_{2}$, a despeito da dispersão dos teores de álcalis em algumas análises, e negativas para $\mathrm{TiO}_{2}, \mathrm{FeO}_{7}, \mathrm{MnO}, \mathrm{CaO}$ e $\mathrm{P}_{2} \mathrm{O}_{5}$ (Fig. 4). Relações positivas são também mostradas para $\mathrm{Rb}$ e $\mathrm{Zr}$, além de sugeridas para $\mathrm{Nb}, \mathrm{Y}, \mathrm{La}, \mathrm{Ce}$ e Nd; já as negativas são visíveis para $\mathrm{Cr}$ e $\mathrm{Ni}$, e, de forma menos 
evidente, para Sr e Ba (Figs. 5 e 6).

O comportamento dos elementos incompatíveis normalizado para o manto primitivo (McDonough \&
Sun 1995) (Fig. 7) é similar para as rochas dos dois corpos e microssienitos. Ele tem como feição característica a pronunciada anomalia negativa em $\mathrm{Sr}, \mathrm{P}$ e Ti.
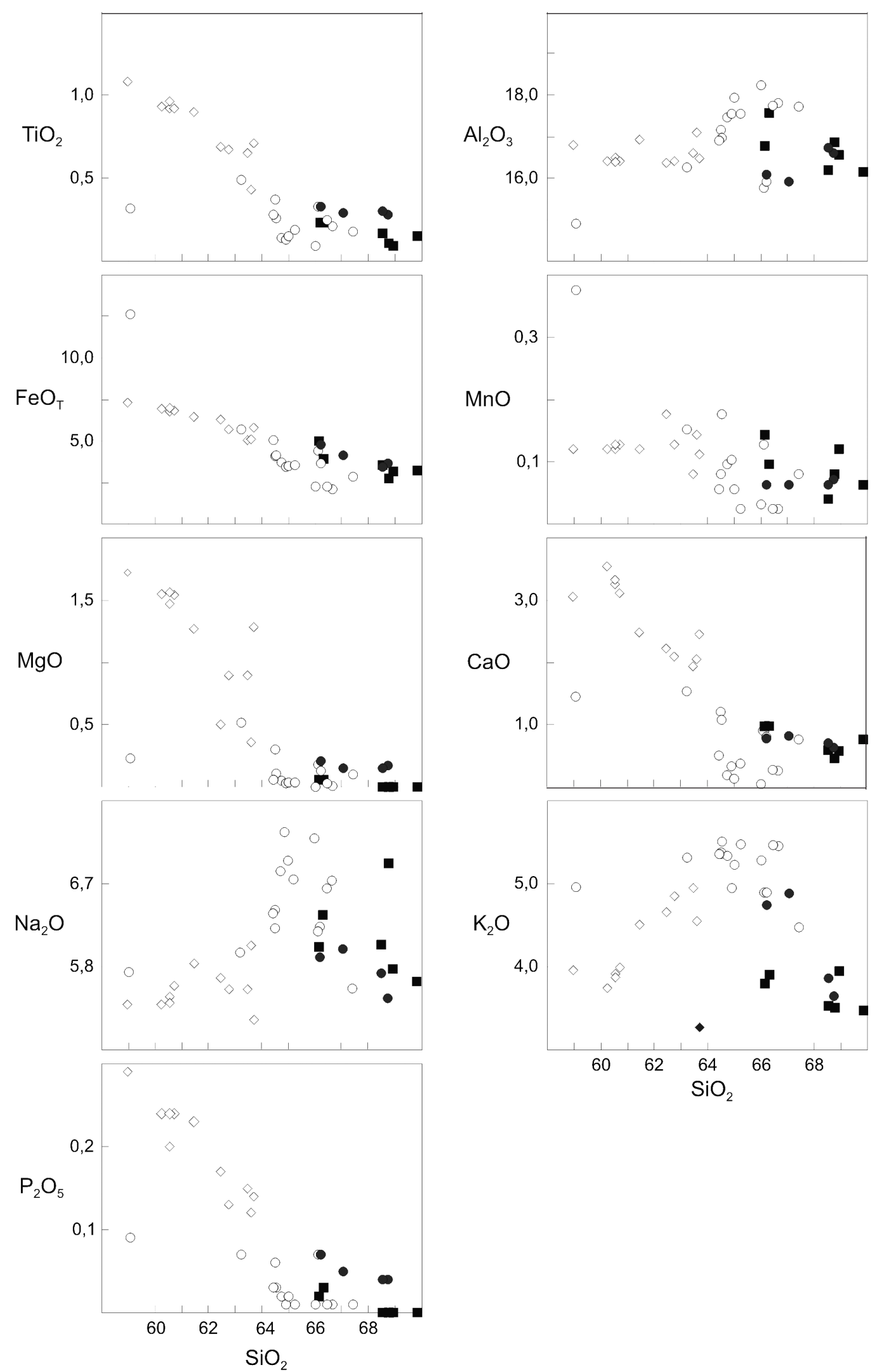

Figura 4 - Diagramas relacionando elementos maiores e sílica nas rochas de Cananéia. Símbolos como na figura 1. 

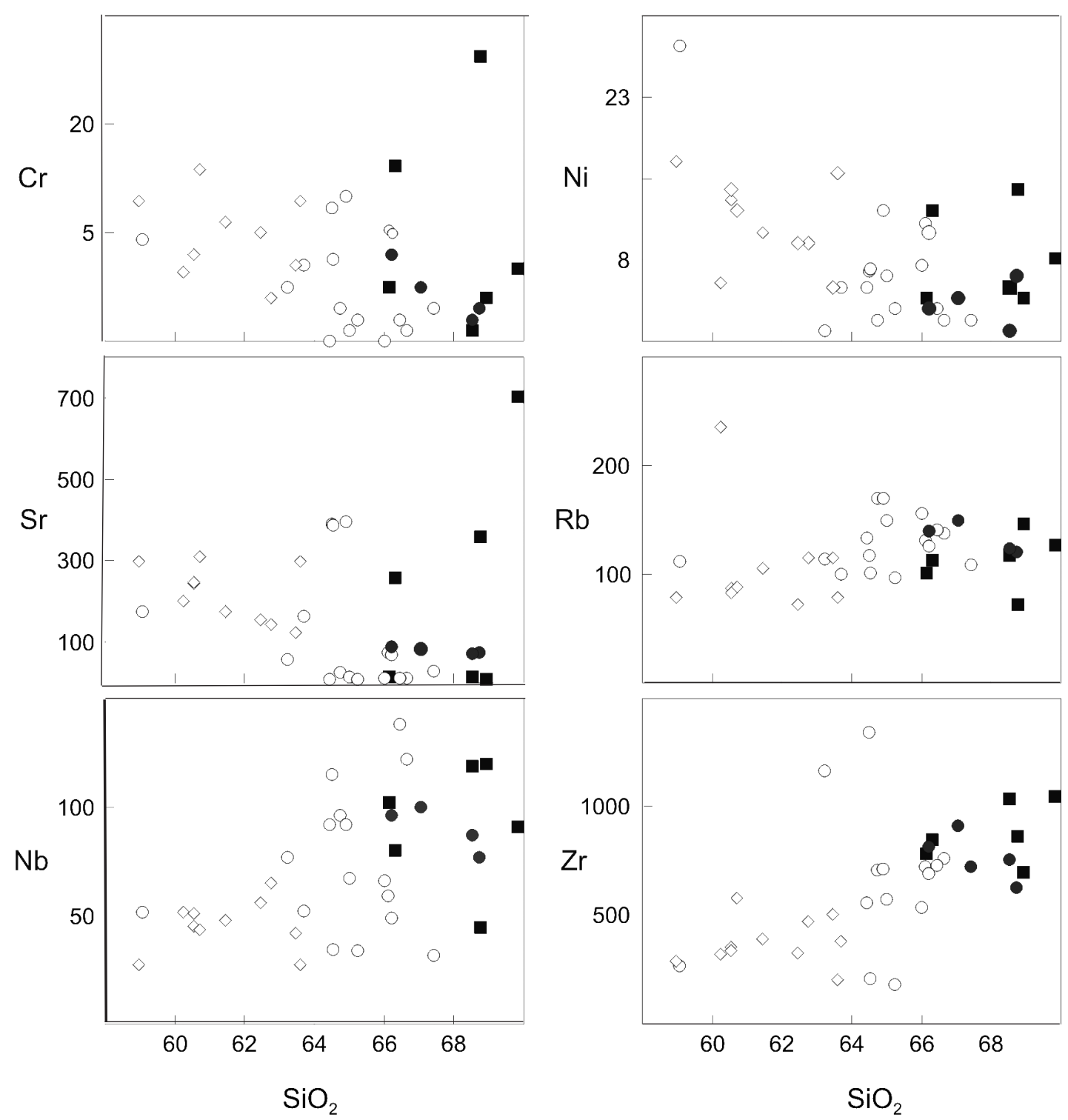

Figura 5 - Diagramas relacionando elementos menores e sílica nas rochas de Cananéia. Símbolos como na figura 1.

Por sua vez, Zr e Nd exibem anomalia positiva, o mesmo ocorrendo, ainda que mais discretamente, com La e Y. A concentração em Ba é extremamente variável (43 a $2242 \mathrm{ppm})$, tendendo a ser maior nos álcali feldspato sienitos, menor nos quartzo-álcali feldspato sienitos e menor ainda nas amostras de diques. A existência de duas suítes, uma mais rica em Ba (>500 ppm) e outra mais pobre $(200 \pm 84 \mathrm{ppm})$, como já apontado por $\mathrm{Ru}-$ berti et al. (2005), é também sugerida na figura 6 .

No geral, a distribuição dos elementos incompatíveis nas rochas de Cananéia mostra grandes similaridades com aquela observada em outras intrusões alcalinas brasileiras, sem carbonatitos e reunindo rochas evoluídas, como, por exemplo, as da Província da Serra do Mar (Morbidelli et al. 1995; Enrich et al. 2005).

A distribuição dos elementos terras raras normalizada para os condritos (McDonough \& Sun 1995) apresenta, ao lado da sua alta concentração, o fracionamento das TRL em relação às TRP, uma feição típica de séries alcalinas em geral (Fig. 8). A salientar ainda a mudança de comportamento das TRM e TRP, que se torna mais uniforme, devido à remoção do líquido de uma ou mais fases com alto coeficiente de partição cristal/líquido, como apatita e titanita, durante o processo de diferenciação magmática (cf. Gomes et al. 1987). Esse padrão, onde a curva de distribuição assume forma caracteristicamente côncava junto às TRM e TRP, está também presente em várias associações sieníticas de ocorrências alcalinas brasileiras (p.ex. Piratini, Barbieri et al. 1987; Tunas, Gomes et al. 1987; Morro Redondo, Brotzu et al. 1989; Passa Quatro, Brotzu et al. 1992, entre outras). O enriquecimento em TRL é ligeiramente maior nos quartzo-álcali feldspato sienitos $\left(\mathrm{La}_{\mathrm{N}} / \mathrm{Sm}_{\mathrm{N}}\right.$ : 1,58-12,44; $\mathrm{Ga}_{\mathrm{N}} / \mathrm{Yb}_{\mathrm{N}}$ : 1,51-2.46) quando comparado ao dos álcali feldspato sienitos $\left(\mathrm{La}_{\mathrm{N}} / \mathrm{Sm}_{\mathrm{N}}\right.$ : 1,58-6,60; $\left.\mathrm{Ga}_{\mathrm{N}} / \mathrm{Yb}_{\mathrm{N}}: 1,44-2,06\right)$, contudo, a curva de distribuição dos ETR para as duas litologias é, no geral, muito similar, notando-se apenas maior dispersão nos valores das razões $\mathrm{La}_{\mathrm{N}} / \mathrm{Yb}_{\mathrm{N}}(5,00-28,41)$ e $\mathrm{La}_{\mathrm{N}} / \operatorname{Sm}_{\mathrm{N}}(1,58-12,44)$ e menor nos de $\mathrm{Ga}_{\mathrm{N}} / \mathrm{Yb}_{\mathrm{N}}(1,44-2,66)$. Já o padrão para 

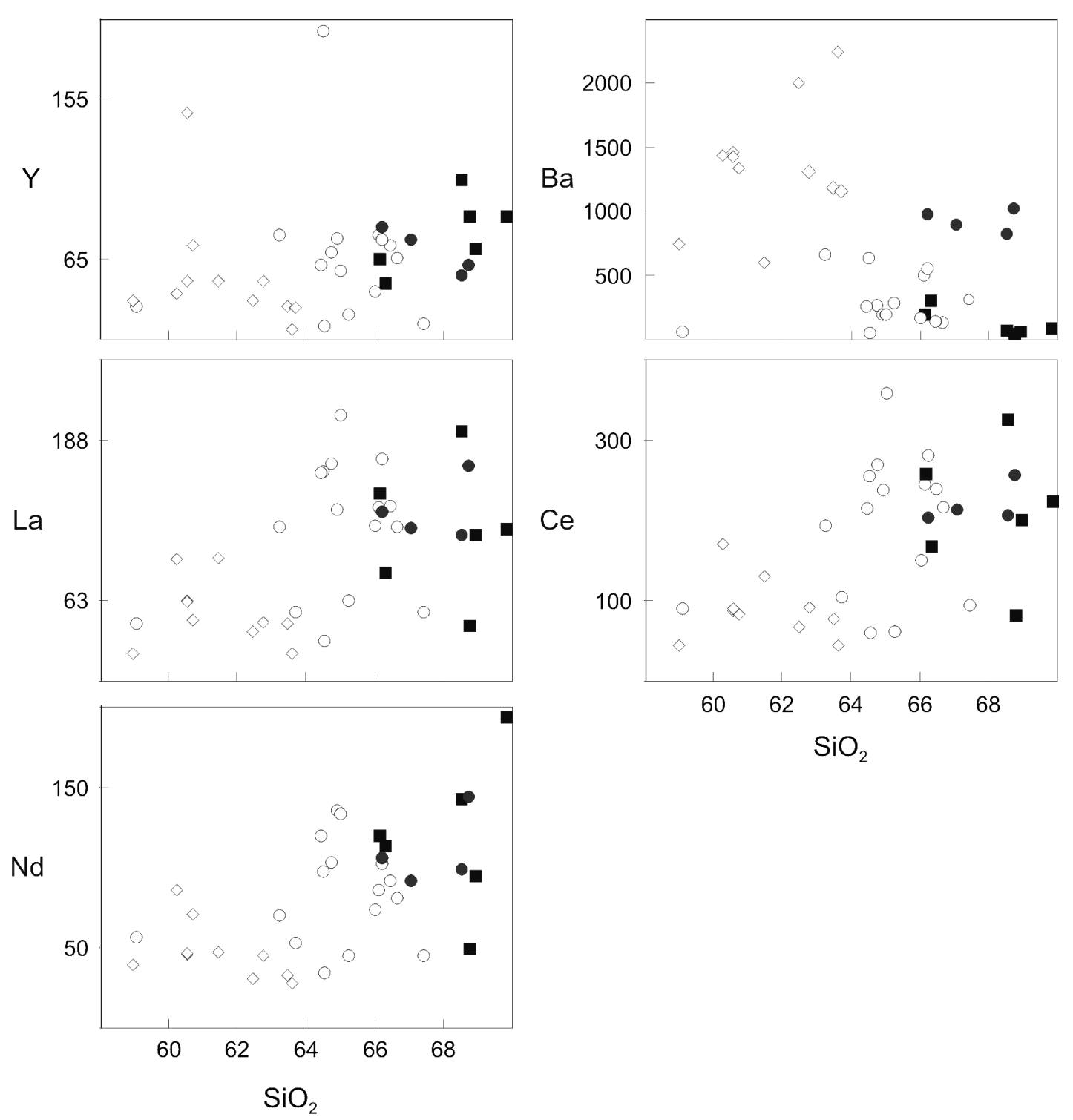

Figura 6 - Diagramas relacionando elementos menores e sílica nas rochas de Cananéia. Símbolos como na figura 1.

as hipoabissais não difere de modo acentuado daquele relativo aos tipos intrusivos, exibindo as mesmas características gerais e razões $\mathrm{La}_{\mathrm{N}} / \mathrm{Yb}_{\mathrm{N}}(7,53-9,36), \mathrm{La}_{\mathrm{N}} / \mathrm{Sm}_{\mathrm{N}}$ $(3,00-4,06) \mathrm{e} \mathrm{Ga}_{\mathrm{N}} / \mathrm{Yb}_{\mathrm{N}}(1,51-2,18)$ próximas às definidas acima. Ainda merece realce na figura 8 , a pronunciada anomalia negativa de $\mathrm{Eu}\left(\mathrm{Eu} / \mathrm{Eu}^{*}=0,20\right.$ a 0,89$)$, possivelmente devida à remoção de feldspato, como admitido previamente por Ruberti et al. (2005).

GEOQUÍMICA ISOTÓPICA Determinações das razões isotópicas iniciais de ${ }^{87} \mathrm{Sr} /{ }^{86} \mathrm{Sr}$ e ${ }^{144} \mathrm{Nd} /{ }^{143} \mathrm{Nd}$, calculadas com base no valor de 83,6 Ma para a idade do maciço de Cananéia, foram efetuadas em amostras provenientes dos dois corpos (Tab. 2).

As razões ${ }^{87} \mathrm{Sr} /{ }^{86} \mathrm{Sr}$ obtidas para os álcali feldspato sienitos variam de 0,7065 a 0,70700 e para os quartzo-álcali feldspato sienitos de 0,7054 a 0,7078 . Da tabela constam também os teores variáveis de $\operatorname{Sr}(5,46$ a $246,25 \mathrm{ppm}$ ), cujas baixas concentrações poderiam res- ponder por algumas das diferenças encontradas nos valores da razão inicial. Já os valores da razão ${ }^{144} \mathrm{Nd} /{ }^{143} \mathrm{Nd}$ para as duas litologias são, respectivamente, de 0,51221 a 0,51241 e de 0,51206 a 0,51207 , sendo, portanto, ligeiramente inferiores na segunda.

Examinando o conjunto de dados isotópicos disponíveis paras as ocorrências alcalinas associadas ao Lineamento Guapiara, Ruberti et al. (2005) forneceram valores de ${ }^{87} \mathrm{Sr} /{ }^{86} \mathrm{Sr}$ dentro do intervalo 0,70452 0,70489 para Jacupiranga, Juquiá e Pariquera-Açu, e de $0,70709( \pm 0,00070)$ para Cananéia. À exceção de duas das amostras investigadas, ambas com baixo teor de $\mathrm{Sr}$ (cf. Tab. 2), as demais apresentaram valores para a razão inicial compatíveis com os daqueles autores.

Os valores de $\varepsilon_{\mathrm{Sr}}$ para os álcali feldspato sienitos são de +27 a +32 , e para os quartzo-álcali feldspato sienitos de +11 a +45 . Por outro lado, os valores de $\varepsilon_{\mathrm{Nd}}$ mostram intervalos de variação bem menores, de -2 a -6 para as primeiras rochas, sendo praticamente constantes, 

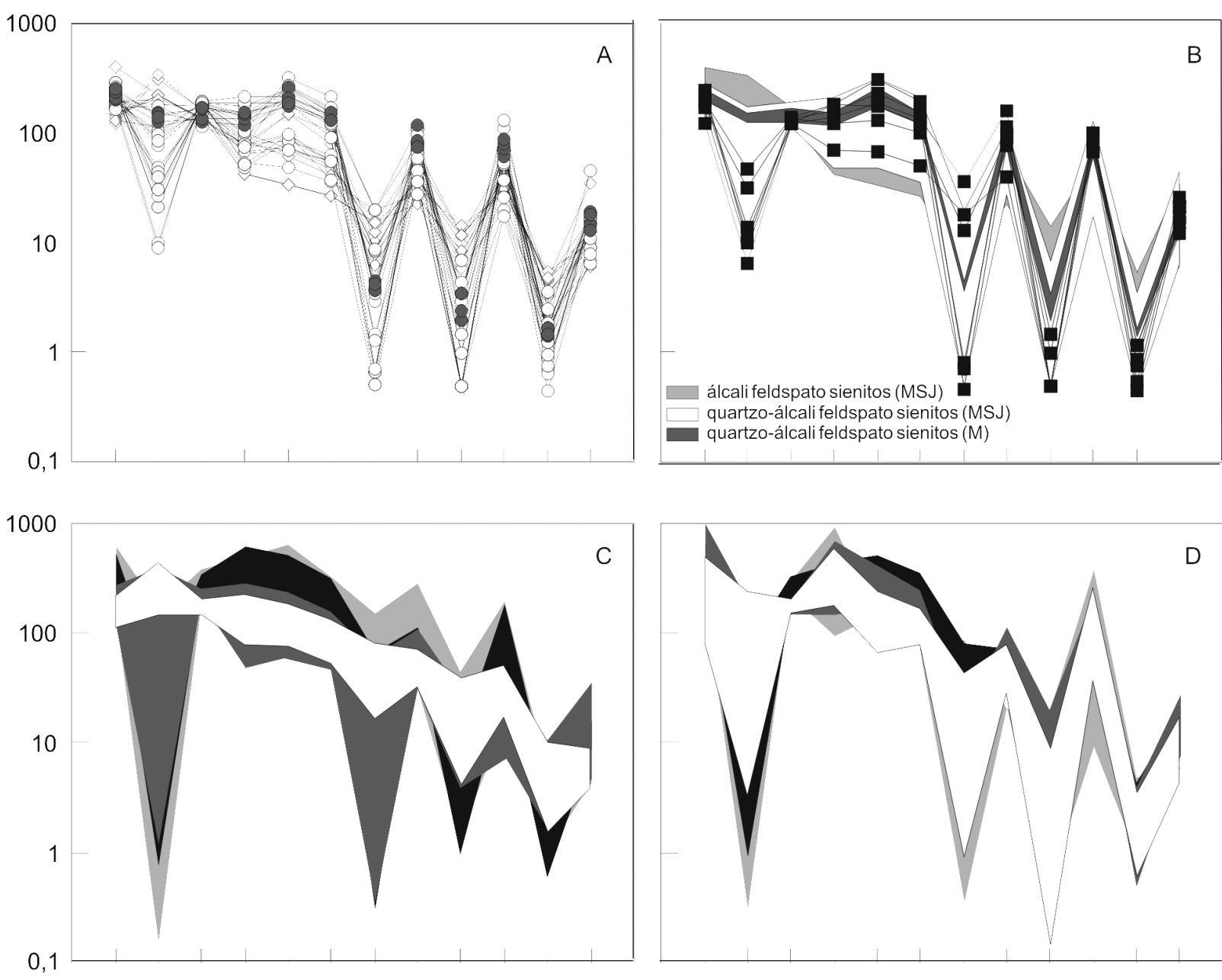

$\mathrm{Rb} \mathrm{Ba} \mathrm{K} \mathrm{Nb}$ La Ce Sr Nd P $\mathrm{Zr}$ Ti $\mathrm{Y}$

$\mathrm{Rb} B \mathrm{Ba} \mathrm{Kb}$ La $\mathrm{Ce} \mathrm{Sr} N \mathrm{Nd} \quad \mathrm{P} \quad \mathrm{Zr}$ Ti $\mathrm{Y}$

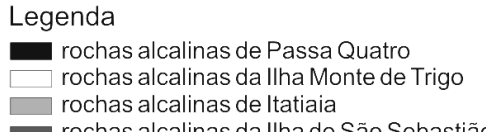

rochas alcalinas da llha de São Sebastião

Figura 7 - Diagramas de elementos incompativeis normalizados segundo o manto primitivo (McDonough \& Sun 1995) para as rochas de Cananéia. O gráfico A reúne intrusivas do Morro de São João e de Morrete. Já o B traz os microssienitos do Morro de São João, ao lado dos campos correspondentes aos tipos intrusivos. Símbolos como na figura 1. Os gráficos C e D representam ocorrências sieníticas da região sudeste do país. Fonte de dados: Spinelli (2007).

em torno de -9 , para as segundas. No diagrama $\varepsilon_{\mathrm{Sr}}$ versus $\varepsilon_{\mathrm{Nd}}$ (Fig. 9), as análises projetam-se no quadrante enriquecido e, à exceção de uma única amostra (53), estão alinhadas paralelamente à extensão do "low-Nd mantle array" de Hart et al. (1986) (Paraguay array de CominChiaramonti et al. 2007), incluindo material não-contaminado associado ao magmatismo toleítico e alcalino (rochas silicáticas e carbonatíticas) da Província ParanáAngola-Etendeka (Comin-Chiaramonti et al. 1999).

O gráfico possibilita também notar que essas rochas parecem constituir um campo à parte daquele correspondente às ocorrências alcalinas relacionadas com a Província do Arco de Ponta Grossa, aí incluídos os corpos do Cretáceo Inferior e Superior.

Cálculos da idade modelo $\left(\mathrm{T}_{\mathrm{DM}}\right.$, manto em- pobrecido), feitos com base na equação de De Paolo (1988), deram números variáveis entre 1,0 e 1,6 Ga para as rochas de Cananéia, com valores médios de $1,2 \pm 0,2 \mathrm{Ga}(f=4)$ para os álcali feldspato sienitos e de $1,5 \pm 0,1 \mathrm{Ga}(f=4)$ para os quartzo-álcali feldspato sienitos (Tab. 2). Esses valores são superiores aos fornecidos por Ruberti et al. (2005) para outros corpos alcalinos da Província do Arco de Ponta Grossa (Jacupiranga, 744979 Ma; Juquiá, 889-1001 Ma; Mato Preto, 668-735 Ma; Tunas, $863 \mathrm{Ma}$, juntamente com os diques e plugs associados, 731-742 Ma) e também por Siga Jr. et al. (2007), de $1019 \mathrm{Ma}$, para o último maciço. À vista dos dados disponíveis na ocasião, Ruberti et al. (2005) definiram dois aparentes episódios de enriquecimento metassomático do manto subcontinental associados aos li- 

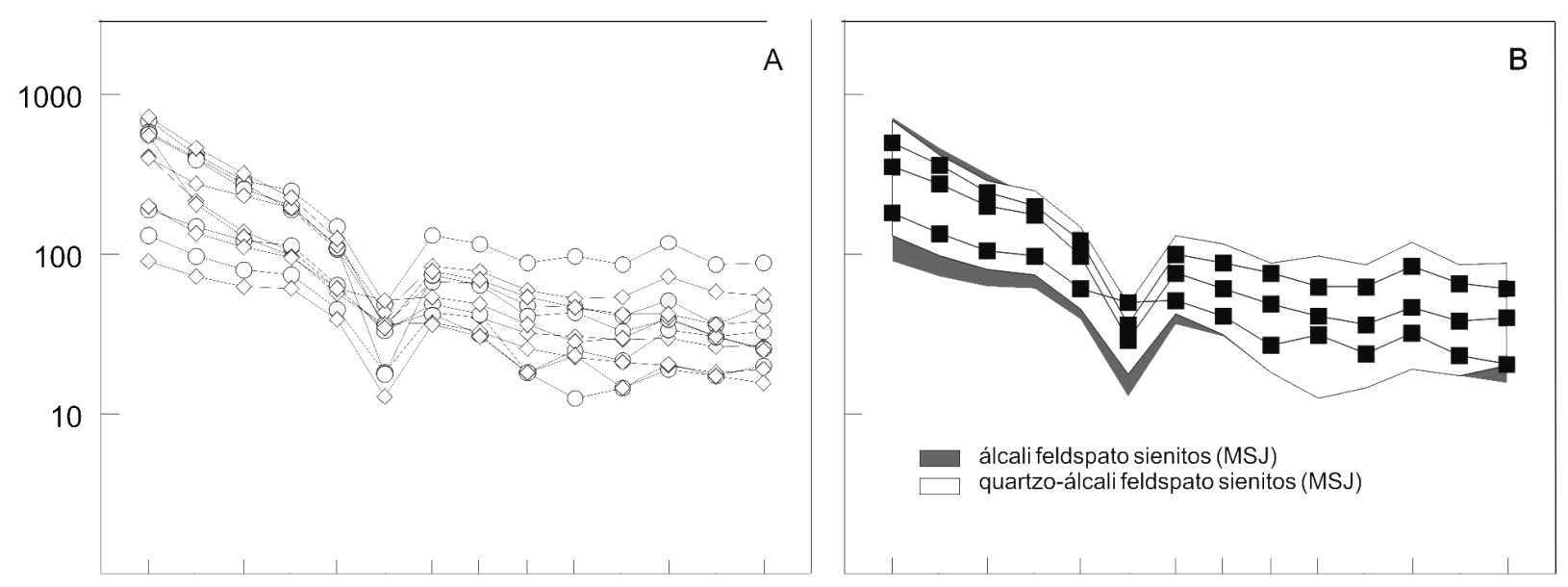

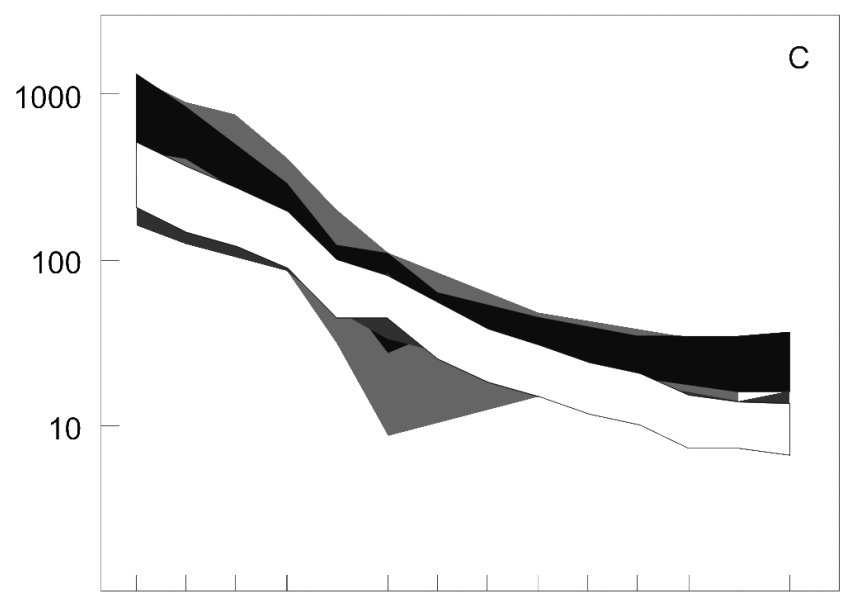

La Ce Pr NdSm Eu Gd Tb Dy Ho Er Tm Yb Lu Legenda
rochas alcalinas de Passa Quatro
rochas alcalinas da Ilha Monte de Trigo
rochas alcalinas de Itatiaia
rochas alcalinas da Ilha de São Sebastião

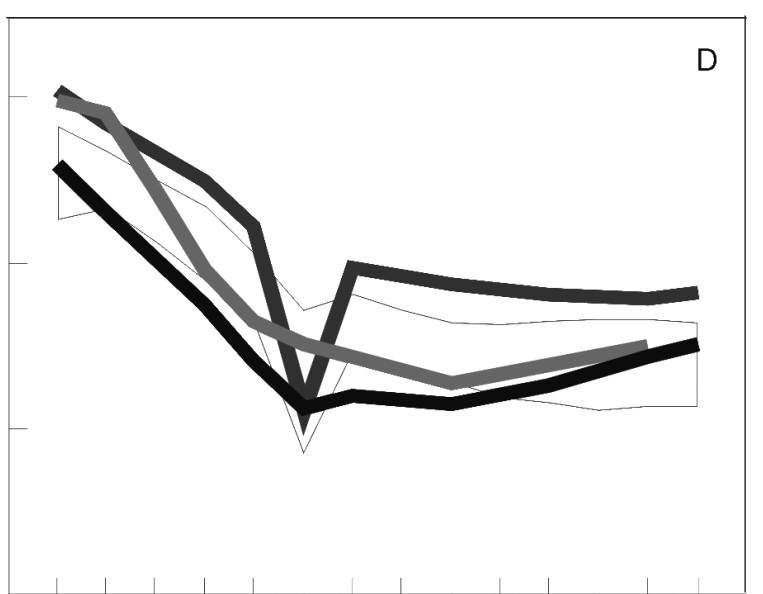

La Ce Pr NdSm Eu Gd Tb Dy Ho Er Tm Yb Lu

Figura 8 - Diagramas de elementos terras raras normalizados segundo os condritos (McDonough \& Sun 1995 para as rochas de Cananéia. O gráfico A reúne intrusivas do Morro de São João. Por sua vez, o B contém os campos de distribuição dessas rochas e os pontos referentes às hipoabissais do Morro de São João. Símbolos como na figura 1. Os gráficos C e D representam ocorrências sieníticas da região sudeste do país. Fonte de dados: Spinelli (2007).

neamentos do Arco de Ponta Grossa: 0,9 Ga (Guapiara) e $0,7 \mathrm{Ga}$ (São Jerônimo-Curiúva). Da mesma forma, os dados obtidos para as rochas de Cananéia são maiores que os reunidos por Enrich et al. (2005) para as grandes intrusões sieníticas da Província da Serra do Mar (Ilha de São Sebastião, 619-819 Ma; Itatiaia, 838-928 Ma; Passa Quatro, 872-899 Ma), e outros corpos dessa região ( $800 \pm 50 \mathrm{Ma}$, cf. Thompson et al. 1998), que os do maciço máfico-ultramáfico de Ponte Nova $(945 \pm 115$ Ma, cf. Azzone 2008) e, ainda, os das ocorrências da Ilha Monte de Trigo (650 100 Ma, cf. Enrich 2005) e Poços de Caldas (692 \pm 54 Ma, cf. Ulbrich et al. 2003).

No confronto das idades modelo disponíveis para ocorrências alcalinas da porção sudeste do território brasileiro, é importante assinalar a maior similaridade entre os valores obtidos para Cananéia com aqueles relativos aos dois complexos alcalino-carbonatíticos de Santa Catarina, Anitápolis e Lages, respectivamente, do Cretáceo Inferior e Cretáceo Superior. Scheibe et al. (2005) listam valores de $1300 \pm 100$ Ma para o primeiro e de $1200 \pm 200$ Ma para o segundo, sendo esse caráter bimodal interpretado por Traversa et al. (1996) como sugestivo da presença de fontes mantélicas submetidas a processos metassomáticos em épocas distintas.

Por outro lado, o exame das ocorrências alcalinas da borda ocidental da Bacia do Paraná possibilita verificar a existência de idades modelo mais antigas para as intrusões potássicas do Cretáceo Inferior encontradas nas regiões norte-nordeste do Paraguai (CominChiaramonti et al. 1997). Estes autores caracterizaram um segundo grupo de ocorrências com idades mais jovens, aí também incluídas as lavas basálticas da Forma- 
Tabela 2 - Composições isotópicas de Sr e Nd e concentrações de Rb, Sr, Sm e Nd para as rochas de Cananéia. Razão inicial ${ }^{87} \mathrm{Sr}{ }^{86} \mathrm{Sr}$ (Ro) calculada para 83,6 Ma; (*) dados de Rb e Sr extraídos de Spinelli (2000); ${ }^{143} \mathrm{Nd} /{ }^{144} \mathrm{Nd}=0,51344$ e $\mathrm{Sm} / \mathrm{Nd}=0,222$ (cf. Michard et al. 1985), ${ }^{147} \mathrm{Sm} /{ }^{144} \mathrm{Nd}{ }_{\text {CHUR }}=0,1967$ (cf. Faure 1986).

\begin{tabular}{|c|c|c|c|c|c|c|c|c|c|c|c|c|c|c|c|c|c|c|c|}
\hline Amostra & Material & $\mathrm{Rb}$ & $\mathrm{Sr}$ & ${ }^{87} \mathrm{Rb} /{ }^{86} \mathrm{Sr}$ & ${ }^{87} \mathrm{Sr} /{ }^{86} \mathrm{Sr}$ & Erro & $\mathrm{R}_{0}$ & $\varepsilon_{0}$ & $\varepsilon_{\mathrm{Sr}}$ & $\Sigma \mu$ & $\mathrm{Nd}$ & $\left|{ }^{147} \mathrm{Sm} /{ }^{144} \mathrm{Nd}\right|$ & ${ }^{143} \mathrm{Nd} /{ }^{144} \mathrm{Nd}$ & Erro & $\mathrm{f}_{\mathrm{Sm} / \mathrm{Nd}}$ & $\mathrm{R}_{0 \mathrm{i}}$ & $\mathrm{e}_{0}$ & $\begin{array}{l}T_{\mathrm{DM}} \\
(\mathrm{Ga})\end{array}$ & $\varepsilon_{\mathrm{Nd}}$ \\
\hline $7 *$ & rocha total & 129 & 178,06 & 2,097 & 0,70936 & 0,00005 & 0,70687 & 69,02 & 32,17 & 11,74 & 58,12 & 0,1221 & 0,51221 & 0,00001 & $-0,38$ & 0,51222 & $-6,91$ & 1,3 & $-6,19$ \\
\hline $7 *$ & feld, alcalino & 82,69 & 186,62 & 1,283 & 0,70882 & 0,00008 & 0,70729 & 61,32 & 38,23 & & & & & & & & & & \\
\hline $7 *$ & clinop + anfi & 26,39 & 15,76 & 4,85 & 0,71276 & 0,00006 & 0,707 & 117,25 & 34,05 & & & & & & & & & & \\
\hline $29 *$ & rocha total & 98,52 & 246,25 & 1,158 & 0,70788 & 0,0001 & 0,70673 & 47,98 & 26,99 & 9,57 & 48,59 & 0,1191 & 0,51241 & 0,00005 & $-0,39$ & 0,51241 & $-3,22$ & 1 & $-2,32$ \\
\hline 29 & biotita & 315,9 & 8,68 & 106,593 & 0,82818 & 0,00009 & 0,70163 & 1755,57 & $-42,17$ & & & & & & & & & & \\
\hline $32 \mathrm{~A}$ & rocha total & 82,25 & 236,51 & 1,007 & 0,70793 & 0,00014 & 0,70673 & 48,69 & 30,25 & 10,04 & 49,02 & 0,1238 & 0,51227 & 0,00002 & $-0,37$ & 0,51228 & $-5,75$ & 1,3 & $-5,04$ \\
\hline $32 \mathrm{~A}^{*}$ & feld, alcalino & 93,26 & 245,66 & 1,099 & \begin{tabular}{|l|}
0,70784 \\
\end{tabular} & 0,00007 & 0,70654 & 47,41 & 27,42 & & & & & & & & & & \\
\hline $32 \mathrm{~A}$ & biotita & 312,88 & 7,07 & 130,101 & 0,86673 & 0,00013 & 0,71228 & 2302,77 & 109 & & & & & & & & & & \\
\hline $22 A^{*}$ & rocha total & 168,29 & 13,86 & 35,29 & \begin{tabular}{|l|}
0,74949 \\
\end{tabular} & 0,00007 & 0,70759 & 638,61 & 42,41 & & & & & & & & & & \\
\hline 34 & rocha total & 123,97 & 63,51 & 5,654 & \begin{tabular}{|l|}
0,71352 \\
\end{tabular} & 0,00007 & 0,70681 & \begin{tabular}{|l|}
128,03 \\
\end{tabular} & 31,29 & & & & & & & & & & \\
\hline 38 & rocha total & 138,76 & 36,08 & 11,146 & \begin{tabular}{|l|}
0,72056 \\
\end{tabular} & 0,00007 & 0,70733 & \begin{tabular}{|l|}
227,96 \\
\end{tabular} & 38,65 & & & & & & & & & & \\
\hline $40 *$ & rocha total & 146 & 95,65 & 4,42 & \begin{tabular}{|l|}
0,71195 \\
\end{tabular} & 0,0001 & 0,7067 & \begin{tabular}{|l|}
105,75 \\
\end{tabular} & 29,79 & 22,34 & 113 & 0,1195 & 0,51206 & 0,00002 & $-0,39$ & 0,51206 & $-10,01$ & 1,6 & $-9,09$ \\
\hline $49 *$ & rocha total & 119,29 & 74,97 & 4,608 & 0,71324 & 0,00009 & 0,70777 & 124,06 & 44,93 & 17,07 & 89,51 & 0,1153 & 0,51206 & 0,00002 & $-0,41$ & 0,51206 & $-10,07$ & 1,5 & $-9,24$ \\
\hline $50 *$ & rocha total & 137,31 & 100,53 & 3,955 & 0,7115 & 0,00009 & 0,7068 & 99,36 & 31,24 & 15,55 & 80,99 & 0,1161 & 0,51207 & 0,00002 & $-0,41$ & 0,51207 & $-9,91$ & 1,5 & $-9,05$ \\
\hline 52 & rocha total & 122,51 & 5,46 & 65,437 & 0,78408 & 0,00006 & 0,70639 & 1129,6 & 25,4 & & & & & & & & & & \\
\hline $53^{*}$ & rocha total & 183,89 & 74,67 & 7,132 & 0,71385 & 0,00012 & 0,70538 & 132,72 & 11,05 & 18,93 & 98,99 & 0,1156 & 0,51206 & 0,00001 & $-0,41$ & 0,51206 & $-9,97$ & 1,5 & $-9,04$ \\
\hline
\end{tabular}

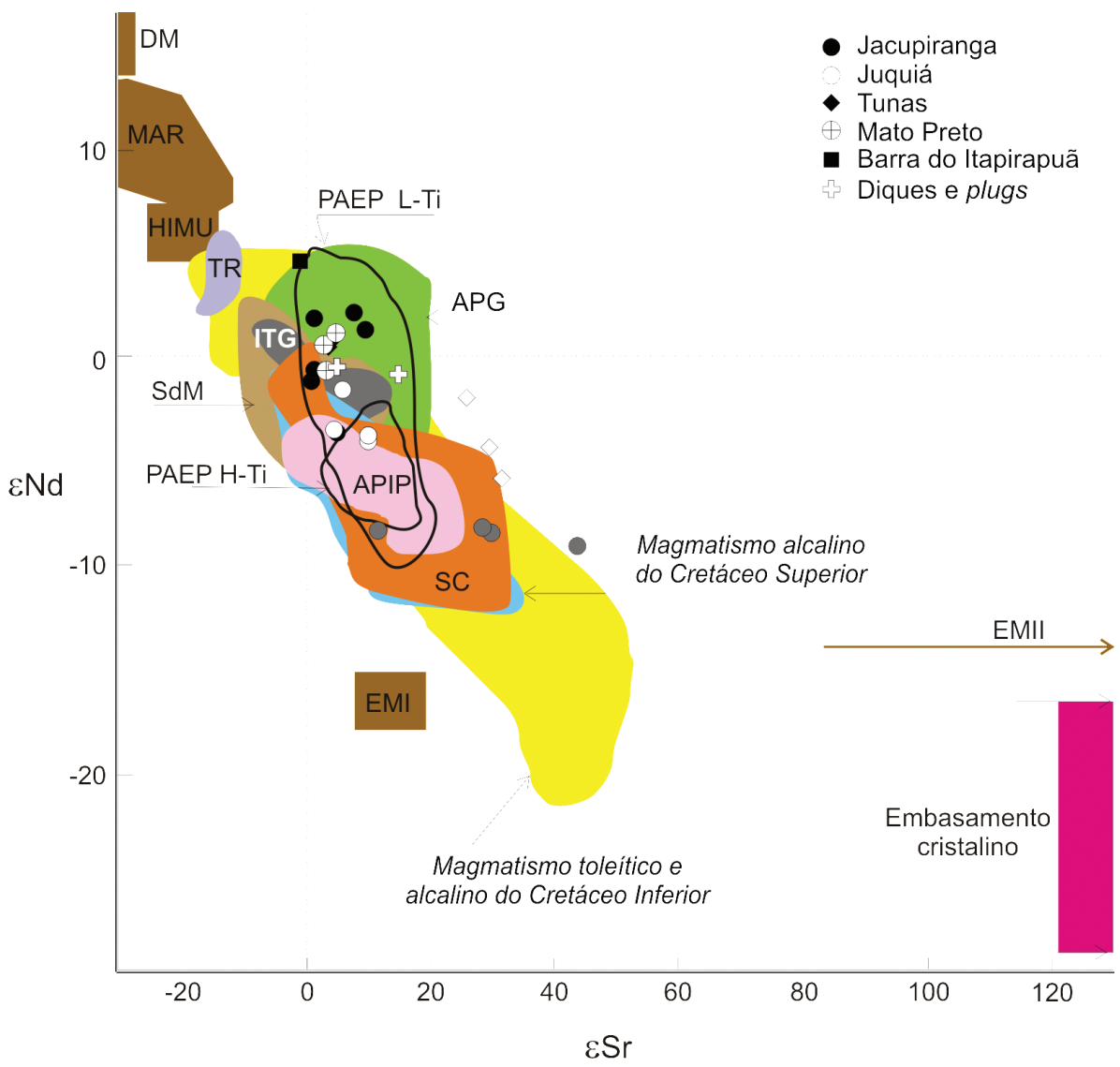

Figura 9 - Diagrama $\varepsilon_{S r}$ versus $\varepsilon_{N d}$ para as rochas de Cananéia. Abreviações: PAEP, Província Paraná-Angola-Etendeka; H-Ti e L-Ti, toleitos com alto e baixo Ti; APG, Arco de Ponta Grossa; APIP, Alto Paranaíba; SC, Anitápolis e Lages; SdM, Serra do Mar; TR, Ilhas Trindade e Martim Vaz; ITG, Ilhas Inaccessible, Tristan e Gough; MAR, Dorsal Meso-Atlântica. DM, EMI, EMII e HIMU, respectivamente, manto empobrecido, mantos enriquecidos e manto de alto $\mu$ (alto ${ }^{238} U^{204} \mathrm{~Pb}$ ). Fonte de dados: Ruberti et al. (2005 e referências) e Enrich et al. (2005 e referências). Símbolos para as rochas de Cananéia: losângulos vazios, álcali feldspato sienitos do Morro de São João; círculos em cinza, quartzo-álcali feldspato sienitos de Morrete. 
ção Serra Geral presentes no território paraguaio, juntamente com os enxames de diques toleíticos do Arco de Ponta Grossa e da região litorânea de São Paulo-Rio de Janeiro. Dele também fazem parte as várias ocorrências das Províncias do Arco de Ponta Grossa e Serra do Mar, como também os numerosos corpos alcalinos da

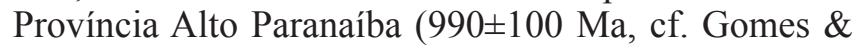
Comin-Chiaramonti 2005).

Os histogramas da figura 10 mostram a distribuição geral das idades modelo das rochas alcalinas de Cananéia, do Paraguai Oriental e basálticas da Formação Serra Geral. Com base nos valores das ocorrências paraguaias e toleíticas, Comin-Chiaramonti et al. (1997) propuseram que dois eventos distintos de metassomatismo ocorridos no Proterozóico (Paleo a Meso: 2000-1400 Ma; Neo: 1000-500 Ma), levando principalmente ao enriquecimento do manto superior subcontinental em elementos incompatíveis, foram os agentes precursores das rochas basálticas e alcalinas da Bacia do Paraná.

Contaminação crustal Os dados isotópicos disponíveis são sugestivos que a grande totalidade das rochas alcalinas e carbonatíticas brasileiras foi originada a partir de fonte mantélica que sofreu pouca ou nenhuma interação crustal (Morbidelli et al. 1995; Brotzu et al. 1997), conclusão também endossada por Comin-Chiaramonti et al. (1997) para as litologias congêneres paraguaias. Exceções a esse quadro estão representadas por pequenos corpos, em geral na forma de diques, presentes em algumas ocorrências, como, por exemplo, em Juquiá (Beccaluva et al. 1992), Tunas (Gomes et al. 1987) ou ainda na região de Cerro Azul (Vasconcellos \& Gomes 1988). Para os corpos alcalinos da Província do Arco de Ponta Grossa, Ruberti et al. (2005) interpretaram as razões ${ }^{87} \mathrm{Sr}{ }^{86} \mathrm{Sr}$ superiores a 0,706 como resultantes de processos de contaminação crustal ou de assimilação-cristalização fracionada, como parece ser o caso de Cananéia.

Uma possível ação desses processos nas rochas de Cananéia foi investigada com o auxílio do diagrama $\mathrm{R}_{\mathrm{o}}$ versus $\mathrm{SiO}_{2}$, mostrando nítida correlação positiva (Fig. 11), com as maiores razões iniciais ${ }^{87} \mathrm{Sr} /{ }^{86} \mathrm{Sr}$ encontradas nas variedades mais ricas em $\mathrm{SiO}_{2}$, tendência essa admitida na literatura como indicativa da ação de um agente contaminante enriquecido em sílica. Considerando apenas a simples mistura de material, Ruberti et al. (2005) chegaram a resultados de até $30 \%$ para uma possível contribuição do contaminante (embasamento cristalino), valores tidos por eles como pouco realísticos e que os levou a propor para essas rochas uma ação conjunta envolvendo processos de cristalização fracionada e assimilação crustal. Correlações positivas, como indicado na figura 11B, são também exibidas pelas rochas alcalinas vizinhas do complexo de Tunas e de alguns diques e plugs aflorando na área de Cerro Azul, no Paraná.

PETROGÊNESE A investigação de diversas intrusões alcalinas da região sul-sudeste do país tem levado à sugestão que as rochas "sieníticas" ali encontradas poderiam resultar da cristalização de magmas basaníticos. Essa hipótese é sustentada pela presença, na for-
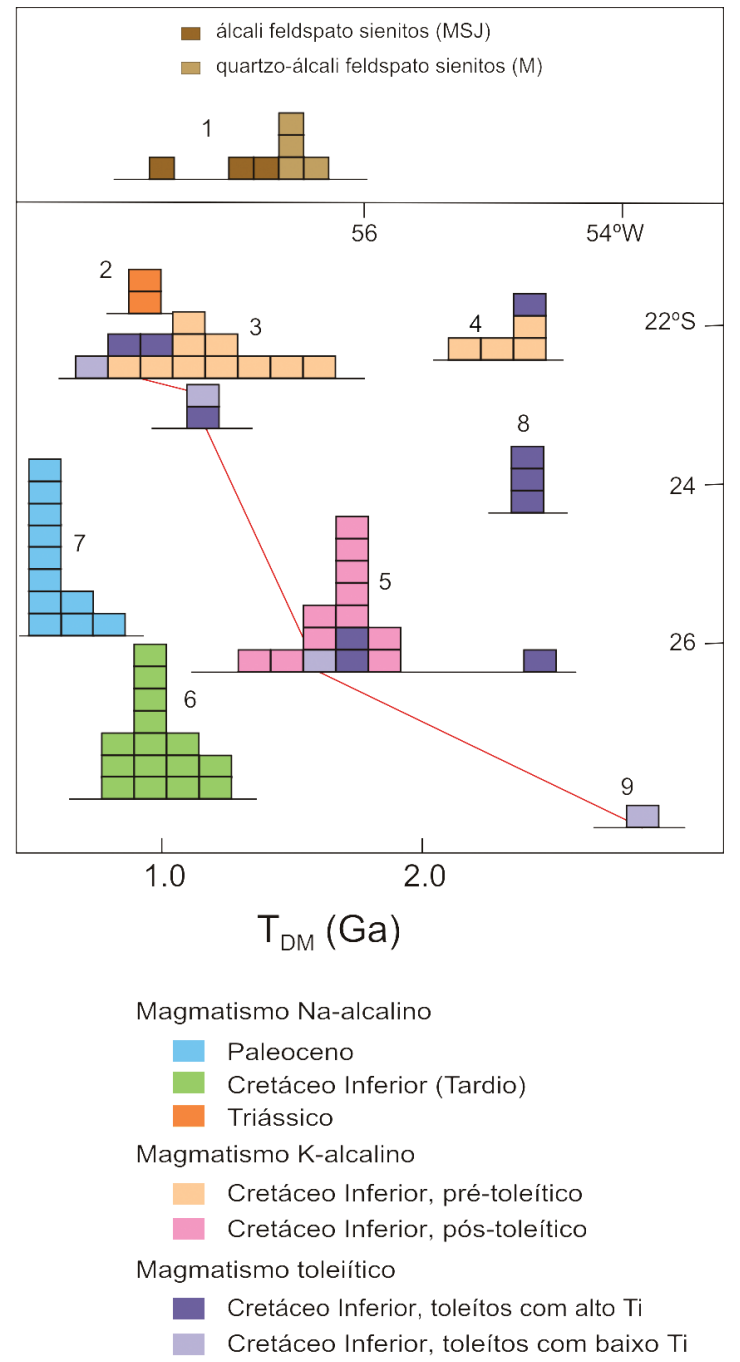

Figura 10 - Distribuição de idades modelo $T_{D M}$ (Ga) para as rochas alcalinas de Cananéia (1) e do Paraguai Oriental (Províncias: 2, Alto Paraguai; 3, Rio Apa; 4, Amambay; 5, Central; 6, Misiones; 7, Assunção; classificação segundo Comin-Chiaramonti et al. 2007), e para as toleiticas da Formação Serra Geral (5, Sapucai; 8, Carayó; 9, Encarnación). Fonte de dados: Comin-Chiaramonti \& Gomes (2005), Comin-Chiaramonti et al. (2007) e Spinelli (2007). A linha em vermelho liga toleitos com baixo teor em Ti.

ma de pequenos diques, de basanito em algumas delas (p.ex. Piratini, Barbieri et al. 1987; Ilha de São Sebastião, Bellieni et al. 1990; Juquiá, Beccaluva et al. 1992; Ilha dos Búzios, Alves 1996; Lages, Traversa et al. 1996; Ponte Nova, Azzone 2008), ao lado da possibilidade de, empregando-se modelamento geoquímico por balanço de massas, derivar as demais rochas associadas a partir desse material, admitido como sendo o tipo petrográfico mais primitivo dessas ocorrências. Sugestões indicativas de um magma parental de afinidade basanítica foram também feitas por Brotzu et al. (1989) para Morro Redondo, por Enrich (2005) para a suíte da Ilha 

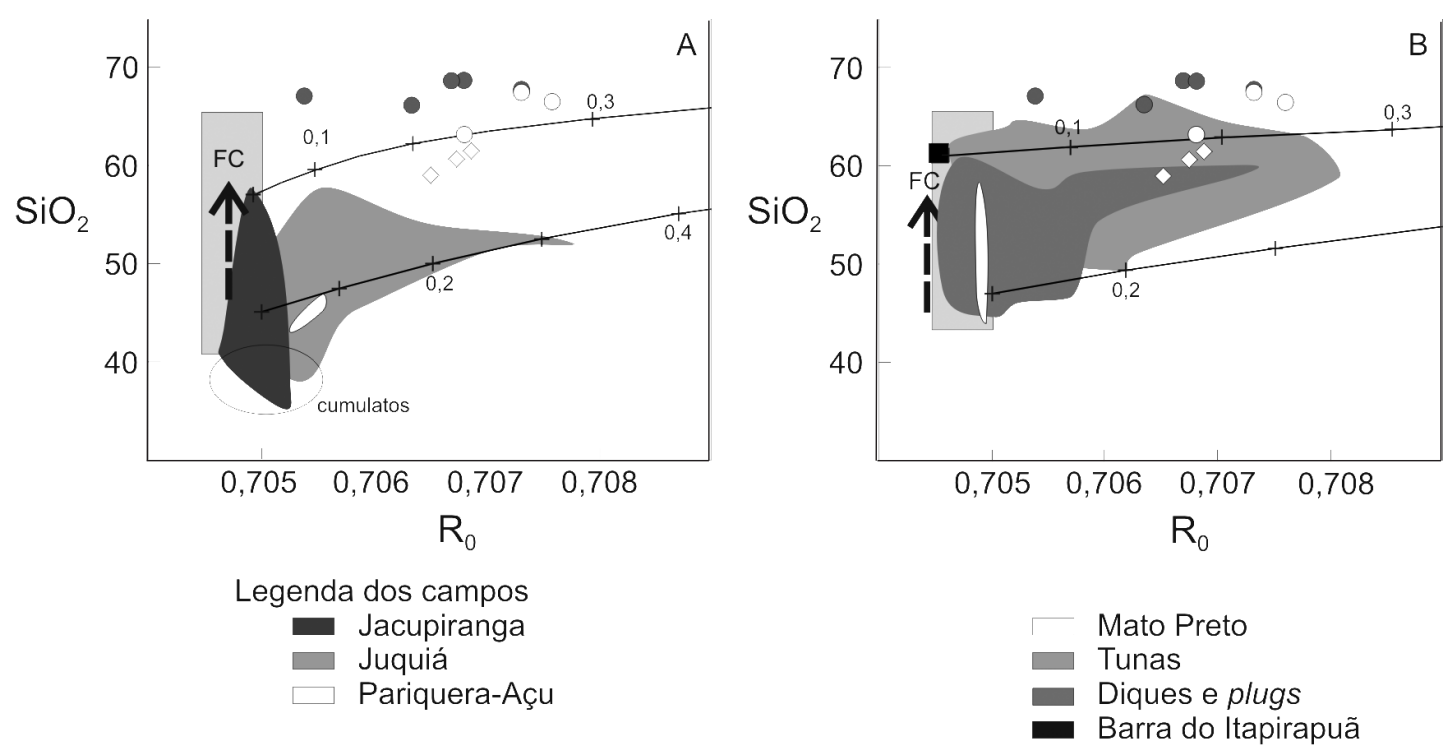

Figura 11 - Diagrama relacionando a razão inicial ${ }^{87} \mathrm{Sr}^{86} \mathrm{Sr}\left(\mathrm{R}_{\mathrm{d}}\right.$ ) e o teor de $\mathrm{SiO}_{2}$ para as rochas de Cananéia e ocorrências associadas aos lineamentos do Arco de Ponta Grossa (Guapiara, A; São Jerônimo-Curiúva, B). Símbolos como na figura 1. Vetor FC indica cristalização fracionada em sistema fechado. Fonte de dados: Ruberti et al. (2005) e Spinelli (2007).

Monte de Trigo e, ainda, por Macciotta et al. (1990) para os corpos da Província Alcalina Terciária de Fortaleza. Por outro lado, magmas parentais de composição basáltica alcalina ou teralítica, ou mesmo ankaratrítica, foram também propostos, respectivamente, para os complexos de Tunas (Gomes et al. 1987), PariqueraAçu (Morbidelli et al. 2000) e alcalino-carbonatítico de Jacupiranga (Morbidelli et al. 1995).

No maciço de Cananéia, as ausências de litologias menos evoluídas $(\mathrm{mg} \#<0,33)$ e de feições indicativas da presença de material mais primitivo (xenocristais e/ou restitos) limitam em muito qualquer consideração a respeito da natureza do magma gerador da intrusão. Disso resulta, que ilações são feitas levando em conta tão-somente as características gerais das rochas, quando comparadas às congêneres de outras ocorrências, além do contexto geológico em que elas estão inseridas. Analisando conjuntamente os diversos corpos alcalinos da Província do Arco de Ponta Grossa, Ruberti et al. (2005) sugeriram para aqueles associados ao Lineamento de Guapiara, onde se enquadra Cananéia, uma origem a partir de magmas de afinidade basanítica (Juquiá) ou basáltica (Pariquera-Açu); já os do Lineamento São Jerônimo-Curiúva de natureza gábrica alcalina (Tunas). Por sua vez, o magmatismo alcalino da Província da Serra do Mar tem no basanito o seu principal magma gerador (Morbidelli et al. 1995; Alves 1996; Brotzu et al. 1997; Enrich 2005; Azzone 2008).

A atividade magmática em Cananéia desenvolveu-se em ambiente de baixa pressão, como também sugerido para outras ocorrências sieníticas do Cretáceo Superior da região sudeste do país, com base na exposição de brechas magmáticas (p.ex. Itatiaia, Lages, Passa Quatro) e presença de estruturas e rochas vulcânicas (p.ex. Piratini, Poços de Caldas, Tunas). A falta de geotermômetros e geobarômetros mais confiáveis e aplicáveis à sua associação mineralógica faz com que a determinação dos parâmetros indicativos das condições de formação do maciço apresente grandes incertezas. Não obstante, temperaturas de cristalização magmática foram calculadas por Spinelli (2007) a partir do termômetro de Watson \& Harrison (1984), que relaciona as concentrações de $\mathrm{P}_{2} \mathrm{O}_{5}$ e $\mathrm{SiO}_{2}$ presentes nas rochas. Os dados coligidos sugerem que a temperatura necessária para que todo o $\mathrm{P}_{2} \mathrm{O}_{5}$ dos álcali feldspato sienitos fosse dissolvido no magma é em torno de $950^{\circ} \mathrm{C}$; para os quartzo-álcali feldspato sienitos a temperatura de dissolução situa-se ao redor de $800^{\circ} \mathrm{C}$, enquanto nos microssienitos ela é inferior a esse valor.

As condições da fugacidade de oxigênio $\left(f \mathrm{O}_{2}\right)$ foram calculadas com base no diagrama clássico de Anderson \& Lindsley (1988) para a composição química de fases opacas coexistentes. Os dados obtidos para os pares magnetita-ilmenita (Fig. 12) indicam para as rochas menos evoluídas valores acima ou próximos ao buffer NNO, refletindo, assim, um ambiente relativamente oxidado, consistente com a ausência de faialita nessas rochas (cf. Brotzu et al. 1997). Por sua vez, aqueles relativos às mais evoluídas colocam-se dominantemente entre os buffers NNO e QFM, apontando para um ambiente menos oxidado que o anterior, a permitir a eventual formação de faialita, como de fato é observado em uma amostra do Morro de São João.

Com base em evidências colhidas em alguns complexos investigados, Morbidelli et al. (1995) generalizaram o entendimento que processos de cristalização fracionada teriam sido responsáveis pela formação e evolução das rochas sieníticas da região sudeste do país. Especificamente no caso de Cananéia, as evidências aqui reunidas, tanto petrográficas quanto químicas, são fortemente sugestivas da ação daqueles processos. A 


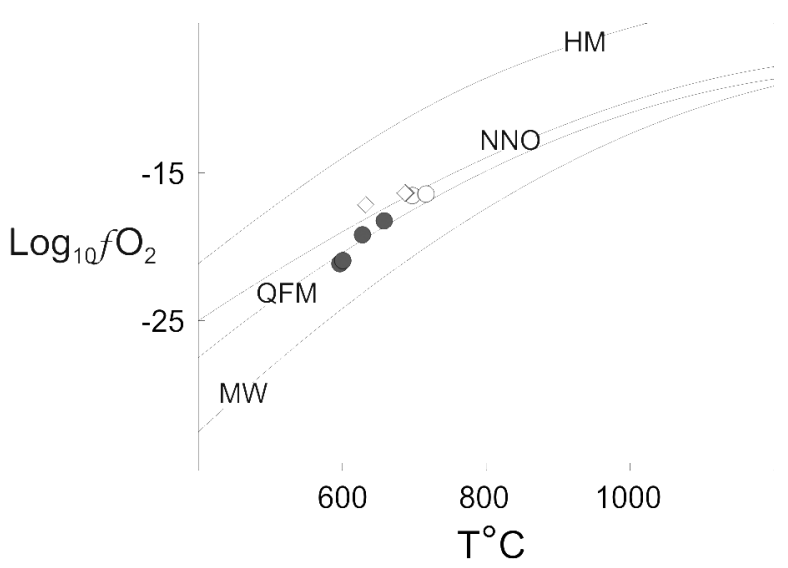

Figura 12 - Diagrama Log $\mathrm{fO}_{2}$ versus $\mathrm{T}^{\circ} \mathrm{C}$ (cf. Andersen \& Lindsley 1988) para os pares magnetitailmenita das rochas de Cananéia. Buffers: HM, hematita-magnetita; NNO, níquel-óxido de níquel; QFM, quartzo-faialita-magnetita; $M W$, magnetitawüstita. Símbolos como na figura 1.

seqüência de cristalização mineral inicial (plagioclásio + clinopiroxênio + anfibólio + minerais opacos + titanita + apatita) definida texturalmente guarda concordância com as variações químicas presentes nos minerais, e mostradas nos gráficos de Harker para rochas (Figs. 4 a 6).

A seqüência evolutiva das rochas de Cananéia é ilustrada na figura 13 (sistema petrogenético residual de Hamilton \& MacKenzie 1965), reunindo as concentrações dos minerais normativos quartzo, nefelina e kalsilita. No diagrama, observa-se que todas as rochas estão projetadas no seu campo superior, o saturado a supersaturado em sílica, e que se dispõem concordante- mente à tendência geral no sentido do mínimo riolítico, sugerida para processos de assimilação-cristalização fracionada (AFC). Essa tendência é compatível com o acentuado fracionamento de feldspato alcalino, principalmente nos estágios finais da evolução magmática, bem como consistente com o baixo teor em K, $\mathrm{Sr}$ e $\mathrm{Ba}$ (Figs. 4 a 6), natureza mais sódica do clinopiroxênio e anfibólio, e maior riqueza em $\mathrm{Fe}^{3+}$ da mica das rochas mais diferenciadas, os microssienitos, com valores de $\mathrm{mg} \#<0,03$. E ainda indicada pela característica e pronunciada anomalia negativa em Eu para todas as rochas da intrusão (Fig. 8B). Essa evolução é também coerente com as variações exibidas nos diagramas de Harker, onde os teores de $\mathrm{Al}_{2} \mathrm{O}_{3}, \mathrm{Na}_{2} \mathrm{O}, \mathrm{K}_{2} \mathrm{O}, \mathrm{Rb}, \mathrm{Nb}$ e $\mathrm{Zr}$ crescem de modo contínuo relativamente à concentração de $\mathrm{SiO}_{2}$, enquanto os de $\mathrm{TiO}_{2}, \mathrm{FeO}_{\mathrm{t}}, \mathrm{MgO}, \mathrm{CaO}, \mathrm{P}_{2} \mathrm{O}_{5}, \mathrm{Cr}$ e Ni decrescem, quando passando dos álcali feldspato sienitos para os quartzo-álcali feldspato sienitos.

Estudos petrológicos mais recentes sobre as rochas alcalinas e alcalino-carbonatíticas da Plataforma Sul-Americana (p.ex. Traversa et al. 1996; CominChiaramonti et al. 1997, 2002, 2005, 2007; Ruberti et al. 2005; Enrich 2005; Enrich et al. 2005; Velázquez et al. 2006; Spinelli 2007; Azzone 2008) têm convergido em atribuir a sua enorme diversidade composicional e variação cronológica a uma fonte mantélica vertical e lateralmente heterogênea, em pequena e grande escala, representativa de diferentes graus de enriquecimento do manto litosférico. Além disso, eles têm também enfatizado que as assinaturas isotópicas $\mathrm{Sr}-\mathrm{Nd}-\mathrm{Pb}$ dessas rochas são indicativas que os componentes EMI e HIMU desempenharam papel importante no processo de sua formação (Fig. 9). Especificamente para as ocorrências do Paraguai Oriental, Comin-Chiaramonti et al. (2007) associaram o magmatismo alcalino potássico do Cretá-

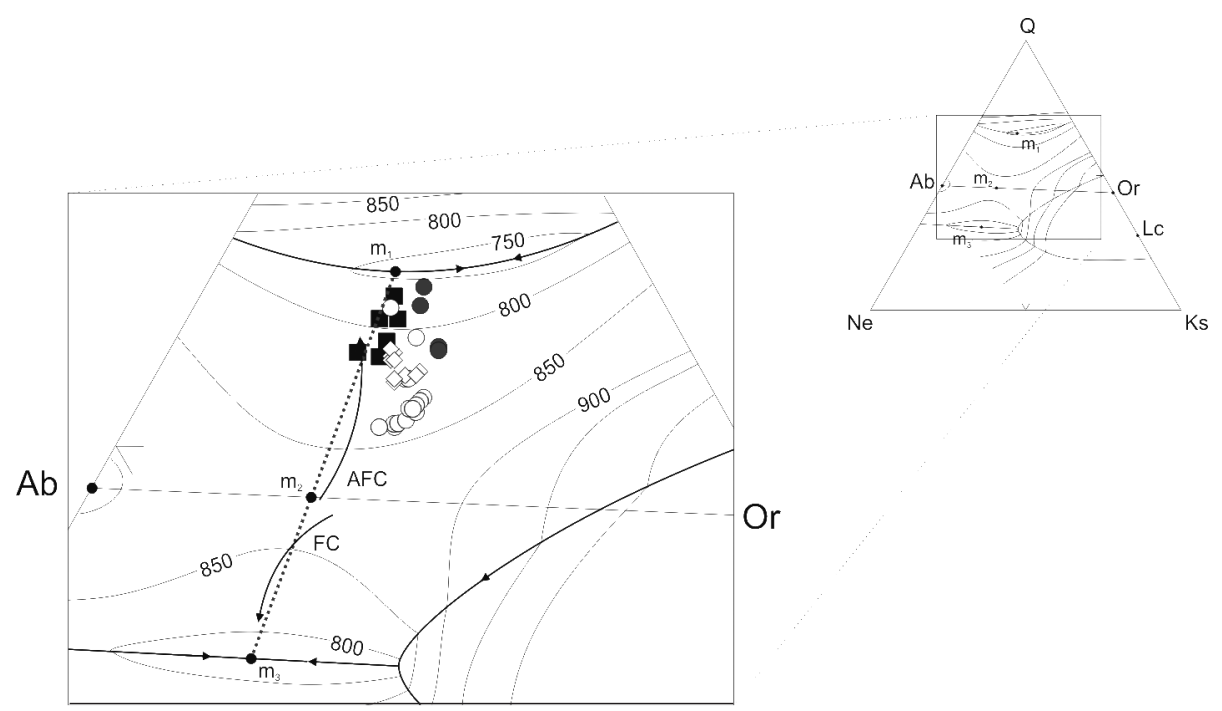

Figura 13 - Diagrama normativo quartzo-nefelina-kalsilita das rochas de Cananéia no sistema petrogenético residual de Hamilton \& MacKenzie (1965) para pressão de água de 1 kbar. Mínimos: $m_{1}$, riolítico; $m_{2}$, magma inicial; $m_{3}$, fonolítico. Símbolos como na figura 1. 
ceo a um extremo e heterogêneo componente mantélico do tipo EMI, enquanto o sódico, que se estende do Triássico ao Paleogeno, a um manto empobrecido. Por outro lado, o cálculo de modelos de fusão para algumas das ocorrências tem sugerido que elas se originaram a partir de uma fonte primária do tipo granada peridotito ou flogopita-granada peridotito, submetida a baixo grau de fusão parcial, e enriquecida não só em elementos incompatíveis, como também em $\mathrm{H}_{2} \mathrm{O}, \mathrm{CO}_{2}$ e $\mathrm{F}$, a julgar pela presença de carbonatitos associados.

A fonte térmica responsável pela fusão e formação do magmatismo alcalino do Cretáceo Superior, especificamente o da Província da Serra do Mar, é atribuída à pluma de Trindade por Gibson et al. (1995, 1999) e Thompson et al. (1998). Estes últimos autores propuseram que o seu desenvolvimento teria se dado pela migração por distâncias consideráveis da pluma para o sul, ao tempo em que a Plataforma Continental se deslocava para o oeste, onde a espessura da litosfera era menor quando comparada àquela do norte, sob o Cráton de São Francisco. Conquanto atraente, o modelo é objeto de contestação na literatura, uma vez que não consegue explicar a gênese e distribuição de algumas ocorrências alcalinas, igualmente do Cretáceo Superior, muito distantes geograficamente do hipotético centro da pluma por ocasião da sua formação, como o são, por exemplo, o complexo alcalino-carbonatítico de Lages, em Santa Catarina, e os numerosos corpos fonolíticos da região de Piratini, no Rio Grande do Sul. Além disso, tem ainda como elementos contestatórios as assinaturas isotópicas tipicamente litosféricas das rochas alcalinas, o visível controle tectônico das numerosas intrusões, associadas à reativação das principais zonas de fraqueza regionais, e a correspondência entre os eventos tectônicos neoproterozóicos que afetaram a região sudeste do país e as idades modelo determinadas para aquelas rochas, refletindo antigas heterogeneidades preservadas no manto subcontinental litosférico.

Outra fonte alternativa de calor para o magmatismo teria sido a gerada pela passagem da pluma de Tristão de Cunha, admitida como agente responsável por uma das maiores áreas de exposição de rochas vulcânicas toleíticas do mundo, a Província Magmática do Paraná, de idade Cretáceo Inferior. Van Decar et al. (1995) mapeou uma zona de baixa velocidade no manto abaixo da Bacia do Paraná e interpretou-a como uma anomalia térmica residual associada a essa pluma, que se deslocava com a placa litosférica. A hipótese é contestada (p.ex. Ernesto 2005; Riccomini et al. 2005) no entendimento, à vista da grande variação cronológica do magmatismo alcalino, que o calor de uma pluma que atingiu a base da litosfera há $130 \mathrm{Ma}$ atrás dificilmente teria condições de ser mantido por tão longo período de tempo.

Mais recentemente vários autores têm se posicionado contra o modelo de plumas mantélicas como fonte de calor para as grandes províncias magmáticas (p.ex. Sheth 1999) e hipóteses alternativas foram propostas (p.ex. Holbrook \& Kelemen 1993; Smith \& Lewis 1999; Ernesto et al. 2002). Estes últimos autores advogam que anomalias térmicas mantélicas de longa duração, re- veladas por anomalias de geóide, teriam condições de fornecer o calor necessário para a geração dos magmas alcalinos. No sudeste do Brasil, as rochas alcalinas e alcalino-carbonatíticas acham-se concentradas em regiões apresentando anomalias positivas do geóide (cf. Molina \& Ussami 1999), que podem estar associadas a material denso e quente de grandes profundidades.

O modelo de Smith \& Lewis (1999) vem sendo também invocado na literatura (p.ex. Comin-Chiaramonti et al. 2002, 2005) para explicar a origem do magmatismo alcalino e alcalino-carbonatítico do Atlântico Sul. Ele pressupõe a ação de forças atuando sobre as placas SulAmericana e Africana, que se movem a diferentes velocidade angulares, e a existência de zonas do manto ricas em voláteis (wetspot) que forçariam o rifteamento a ocorrer paralelamente a suturas N-S preexistentes, correspondendo ao Oceano Adamastor, que separou o cráton do Rio de La Plata, na América do Sul, dos crátons do Kalahari e Congo, no sudeste da África, há 580-550 Ma atrás. O magmatismo alcalino e alcalino-carbonatítico intraplaca teria ocorrido onde os limites das placas de "segunda ordem" (p.ex. Alto Paranaíba, Arco de Ponta Grossa, Arco de Moçâmedes) intersectam os eixos de maior rifteamento, possivelmente relacionados à erosão e circulação do manto continental em direção ao eixo do rifte.

CONSIDERAÇÕES FINAIS Álcali feldspato sienitos e quartzo-álcali feldspato são as principais rochas do maciço de Cananéia, ocorrendo subordinadamente microssienitos com textura variável de mosaica a traquítica. Os sienitos têm feldspato alcalino (mesopertita, dominantemente do tipo hipersolvus) como fase mais abundante e clinopiroxênio+anfibólio, com ampla variação composicional, como minerais ferromagnesianos mais importantes. Biotita, olivina, opacos, apatita, titanita e zircão completam a mineralogia primária.

A seqüência de cristalização dos minerais teve início com os acessórios, seguindo-se plagioclásio cálcico, raramente encontrado como fase isolada, e clinopiroxênio. $\mathrm{O}$ aumento da pressão de água levou à formação de anfibólio em substituição ao clinopiroxênio cálcico e, na seqüência, de biotita, feldspato alcalino e quartzo, o último visivelmente de cristalização mais tardia. Os grãos remanescentes de olivina (faialita) pouco informam sobre as suas relações texturais, ainda que o quimismo aponte para uma cristalização mais tardia do mineral. Atividades tardimagmática a pós-magmática e hidrotermal foram responsáveis por diversas alterações mineralógicas, como sericitização e saussuritização dos feldspatos, uralitização do clinopiroxênio, iddingitização(?) parcial ou total da olivina, aliada à formação de estruturas de exsolução nos feldspatos e opacos.

A associação mineralógica e o teor de $\mathrm{P}_{2} \mathrm{O}_{5}$ das rochas permitem inferir temperaturas de cristalização em torno de $950^{\circ} \mathrm{C}$ para os álcali feldspato sienitos e próximas ou inferiores a $850^{\circ} \mathrm{C}$ para os quartzo-álcali feldspato sienitos e microssienitos. Valores da fugacidade de oxigênio obtidos a partir do quimismo das fases opacas coexistentes apontam para um ambiente de formação relativamente oxidado para as primeiras e menos oxidado 
para as segundas, consistente, respectivamente, com a ausência ou presença de faialita na associação.

Os dados geoquímicos demonstram que as rochas de Cananéia são altamente evoluídas e que a sua formação, com base nas evidências texturais e nos diagramas de variação química para minerais e rochas, se deu por cristalização magmática conjugada à ação de processos de assimilação e contaminação crustal. A seqüência evolutiva álcali feldspato sienitos $\rightarrow$ quartzo-álcali feldspato sienitos + microssienitos é consistente com as variações mostradas no gráfico do sistema petrogenético residual e também concordante com o que se observa nos diagramas de Harker, reunindo $\mathrm{SiO}_{2}$ e os elementos maiores, menores e traços. Nesses diagramas, as concentrações de $\mathrm{Al}_{2} \mathrm{O}_{3}, \mathrm{Na}_{2} \mathrm{O}, \mathrm{K}_{2} \mathrm{O}, \mathrm{Rb}, \mathrm{Nb}$ e $\mathrm{Zr}$ correlacionam-se positivamente com a sílica, enquanto as de $\mathrm{TiO}_{2}, \mathrm{FeO}_{\mathrm{t}}, \mathrm{MgO}$, $\mathrm{CaO}, \mathrm{P}_{2} \mathrm{O}_{5}$, Cr e Ni, negativamente.

A distribuição normalizada dos elementos incompatíveis é uniforme para as variedades intrusivas e hipoabissais e tem como feição mais característica a pronunciada anomalia negativa em $\mathrm{Sr}, \mathrm{P}$ e Ti, ao lado da bem evidente anomalia positiva em $\mathrm{Zr}$ e Nd. A realçar também o comportamento similar das rochas do maciço quando comparadas às de diversas outras ocorrências sieníticas cretácicas da região sudeste do país (p.ex. Ilhas de Búzios, Monte de Trigo e São Sebastião, Itatiaia, Passa Quatro,
Tunas e Ponta do Morro). Já o comportamento do Ba é muito irregular, mostrando picos discretos, positivos e/ou negativos, como também reconhecido nessas ocorrências.

A distribuição normalizada das terras raras, igualmente uniforme para os dois tipos petrográficos acima, apresenta alta concentração desses elementos, fracionamento das TRL relativamente às TRP e significativa anomalia negativa em Eu.

Valores para a idade modelo $\left(\mathrm{T}_{\mathrm{DM}}\right)$ das rochas de Cananéia (1,2 $\pm 0,2$ Ga para os álcali feldspato sienitos e 1,5 $\pm 0,1$ Ga para os quartzo-álcali feldspato sienitos) são muito superiores aos obtidos para as demais ocorrências alcalinas da Província do Arco de Ponta Grossa.

A análise comparativa com outras ocorrências sieníticas cretácicas da região leva a sugerir para as rochas alcalinas de Cananéia uma derivação a partir de um magma parental de composição basanítica, cuja evolução se deu por cristalização fracionada, conjugada à ação de processos de assimilação e contaminação crustal. No diagrama $\varepsilon_{\mathrm{Sr}}$ versus $\varepsilon_{\mathrm{Nd}}$, elas estão projetadas no quadrante enriquecido e se distribuem paralelamente ao trend de "low-Nd mantle array" de Hart et al. (1986).

Agradecimentos Estes são devidos à Fapesp (Procs. 01-10714-3 e 07-57461-9, beneficiário CBG) pelo apoio financeiro à realização do trabalho.

\section{Referências}

Almeida F.F.M. 1971. Condicionamento tectônico do magmatismo alcalino mesozóico do Sul do Brasil e do Paraguai. Anais da Academia Brasileira de Ciências, 43:835836.

Almeida F.F.M. 1983. Relações tectônicas das rochas alcalinas mesozóicas da região meridional da plataforma SulAmericana. Rev. Brasileira de Geociências, 3:139-158.

Alves F.R. 1986. Contribuição ao conhecimento geológico e petrológico da Ilha de Búzios, SP. Tese de Doutoramento, Instituto de Geociências, Univ. de São Paulo, 274p.

Andersen D.J. \& Lindsley D.H. 1988. Internally consistent solution models for Fe-Mg-Mn-Ti oxides: Fe-Ti oxides. American Mineralogist, 73:714-726.

Azzone R.G. 2008. Petrogênese do maciço alcalino máficoultramáfico Ponte Nova (MG-SP). Tese de Doutoramento, Instituto de Geociências, Univ. de São Paulo, 372p.

Barbieri M., Beccaluva L., Brotzu P., Conte A., Garbarino C., Gomes C.B., Loss E.I., Macciotta G., Morbidelli L., Scheibe L.F., Tamura R.M., Traversa G. 1987. Petrological and geochemical studies of alkaline rocks from continental Brazil; 1, The phonolite suite from Piratini, RS. Geochimica Brasiliensis, 1:109-138.

Beccaluva L., Barbieri M., Born H., Brotzu P., Coltorti M., Conte A., Garbarino C., Gomes C.B., Macciotta G., Morbidelli L., Ruberti E., Siena F., Traversa G. 1992. Fractional crystallization and liquid immiscibility process in the alkaline carbonatite complex of Juquiá, São Paulo, Brazil. Journal of Petrology, 33:1371-1404.

Bellieni G., Montes-Lauar C.B., De Min A., Piccirillo E.M., Cavazzini G., Melfi A.J., Pacca I.G. 1990. Early and
Late Cretaceous magmatism from São Sebastião Island (SE-Brazil): geochemistry and petrology. Geochimica Brasiliensis, 4:59-83.

Brotzu, P., Barbieri M., Beccaluva L., Garbarino C., Gomes C.B., Macciota G., Melluso L., Morbidelli L., Ruberti E., Sígolo J.B., Traversa G. 1992. Petrology and geochemistry of the Passa Quatro alkaline complex, southern Brazil. Journal of South American Earth Sciences., 6:237-252.

Brotzu P., Beccaluva L., Conte A., Fonseca M., Garbarino C., Gomes C.B., Leong R., Macciotta, G., Mansur R.L., Melluso L., Morbidelli L., Ruberti E., Sígolo J.B., Traversa G., Valença J.G. 1989. Petrological and geochemical studies of alkaline rocks from continental Brazil. 8 . The syenitic intrusion of Morro Redondo, RJ. Geochimica Brasiliensis, 3:63-80.

Brotzu, P., Gomes, C.B., Melluso, L., Morbidelli L., Morra V., Ruberti E. 1997. Petrogenesis of coexisting $\mathrm{SiO}_{2}$-undersaturated to $\mathrm{SiO}_{2}$-oversaturated felsic igneous rocks: the alkaline complex of Itatiaia, southeastern Brazil. Lithos, 40:133-156.

Comin-Chiaramonti P. \& Gomes C.B. 1996. Alkaline magmatism in central-eastern Paraguay - Relationships with coeval magmatism in Brazil. São Paulo, Edusp-Fapesp, $464 \mathrm{p}$.

Comin-Chiaramonti P. \& Gomes C.B. 2005. Mesozoic to Cenozoic alkaline magmatism in the Brazilian Platform. São Paulo, Edusp/Fapesp, 752p.

Comin-Chiaramonti P., Cundari A., Piccirillo E.M., Gomes C.B., Castorina F., Censi P., De Min A., Marzoli A., Spe- 
ziale S., Velázquez V.F. 1997. Potassic and sodic igneous rocks from Eastern Paraguay: their origin from the lithospheric mantle and genetic relationships with the associated Paraná tholeiites. Journal of Petrology, 38:495-528.

Comin-Chiaramonti P., Cundari A., DeGraff J.M., Gomes C.B., Piccirillo E.M. 1999. Early Cretaceous-Paleogene magmatism in Eastern Paraguay (western Paraná Basin): geological, geophysical and geochemical relationships. Journal of Geodynamics, 28:375-391.

Comin-Chiaramonti P., Gomes C.B., Castorina F., Censi P., Antonini P., Furtado S., Ruberti E., Scheibe L.F. 2002. Anitápolis and Lages alkaline-carbonatite complexes, Santa Catarina State, Brazil: geochemistry and geodynamic implications. Revista Brasileira de Geociências, 32:639-653.

Comin-Chiaramonti P., Gomes C.B., Marques L.S., Censi P., Ruberti E., Antonini P. 2005. Carbonatites from southeastern Brazil: geochemistry, $\mathrm{O}-\mathrm{C}, \mathrm{Sr}-\mathrm{Nd}-\mathrm{Pb}$ isotopes and relationships with the magmatism from the ParanáAngola-Namibia Province. In: Comin-Chiaramonti P. \& Gomes C.B. (eds.) Mesozoic to Cenozoic alkaline magmatism in the Brazilian Platform. São Paulo, Edusp/ Fapesp, p.657-688.

Comin-Chiaramonti P., Marzoli A., Gomes C.B., De Min A., Milan A., Velázquez V.F., Riccomini C., Mantovani M.M.S., Renne P., Tassinari C.C.G., Vasconcelos P.M. 2007. The origin of the post-Paleozoic magmatism in Eastern Paraguay. In: Foulger G.R. \& Jurdy D.M. (eds.) Plates, plumes, and planetary processes. Geological Society of America, Special Paper 430, p.603-633.

De La Roche H.C. 1986. Classification et nomenclature des roches ignées: un essai de restauration de Ia convergence entre systematique quantitative, typologie d'usage et modélisation génétique. Bulletin Societé géologique de France, 2:237-313.

De Paolo D.J. 1988. Age dependence of the composition of continental crust: evidence from $\mathrm{Nd}$ isotopic variations in granitic rocks. Earth Planetary Science Letters, 90:263-271.

Enrich G.A.R. 2005. Petrogênese da suite alcalina da Ilha Monte de Trigo, SP. Tese de Doutoramento, Instituto de Geociências, Universidade de São Paulo, 229p.

Enrich G.A.R., Azzone R.G., Ruberti E., Gomes C.B., Comin-Chiaramonti P. 2005. Itatiaia, Passa Quatro and São Sebastião island, the major alkaline syenitic complex from Serra do Mar region. In: Comin-Chiaramonti P. \& Gomes C.B. (eds.) Mesozoic to Cenozoic alkaline magmatism in the Brazilian Platform. São Paulo, EduspFapesp, p.419-441.

Ernesto M. 2005. Paleomagnetism of the post-Paleozoic alkaline magmatism in the Brazilian Platform: questioning the mantle plume model. In: Comin-Chiaramonti P. \& Gomes C.B. (eds.) Mesozoic to Cenozoic alkaline magmatism in the Brazilian Platform. São Paulo, EduspFapesp, p.689-706.

Ernesto M., Marques L.M., Piccirillo E.M., Molina E., Ussami N., Comin-Chiaramonti P., Bellieni G. 2002. Paraná Magmatic Province-Tristan da Cunha plume system: fixed versus mobile plume, petrogenetic considerations and alternative heat sources. Journal of Volcanology
Geothermal Research, 118:15-36.

Faure G. 1986. Principles of isotope geology. $2^{\text {nd }}$ ed., NewYork, Wiley, 589p.

Freitas R.O. 1947. Eruptivas alcalinas de Cananéia, Estado de São Paulo. Boletim da Faculdade de Filosofia, Ciências e Letras da USP, Geologia, 3:4-35.

Gibson S.A., Thompson R.N., Dickin A.P., Leonardos O.H. 1995. The Late Cretaceous impact of the Trindade mantle plume: evidence from large-volume, mafic potasic magmatism in SE Brazil. Journal of Petrology, 36:189229.

Gibson S.A., Thompson R.N., Weska R.K., Dickin A.P., Leonardos O.H. 1997. Late Cretaceous rift-related upwelling and melting of the Trindade starting mantle plume head beneath western Brazil. Contributions to Mineralogy and Petrology, 126:303-314.

Gomes C.B. \& Comin-Chiaramonti P. 2005. Some notes on the Alto Paranaíba Igneous Province. In: Comin-Chiaramonti P. \& Gomes C.B. (eds.) Mesozoic to Cenozoic alkaline magmatism in the Brazilian Platform. São Paulo, Edusp-Fapesp, p.317-340.

Gomes C.B., Barbieri M., Beccaluva L., Brotzu P., Conte A., Garbarino C., Macciotta G., Melluso L., Morbidelli L., Ruberti E., Scheibe L.F., Tamura R.M., Traversa G. 1987. Petrological and geochemical studies of alkaline rocks from continental Brazil: 2, The Tunas massif, State of Paraná. Geochimica Brasiliensis, 1:201-234.

Hamilton D.L. \& MacKenzie W.S. 1965. Phase equilibria studies in the system $\mathrm{NaAlSiO}_{4}-\mathrm{KAlSiO}_{4}-\mathrm{SiO}_{2}$. Journal of Petrology, 1:56-72.

Hart S.R., Gerlach D.C., White W.M. 1986. A possible new $\mathrm{Sr}-\mathrm{Nd}-\mathrm{Pb}$ mantle array and consequences for mantle mixing. Geochimica et Cosmochimica Acta, 50:15511557.

Hasui Y., Dantas A.S.L., Carneiro C.D.R., Bistrichi C.A. 1981. Embasamento Pré-Cambriano em São Paulo. In: Almeida F.M.F., Hasui Y., Poçano W.L., Dantas A.S.L., Carneiro C.D.R., Melo M.S., Bistrichi C.A. (coords.) Mapa Geológico do Estado de São Paulo na escala 1:500.000. Nota explicativa. Instituto de Pesquisas Tecnológicas, Publicação, 1184:12-45.

Holbrook W.S. \& Kelemen P.B. 1993. Large igneous province on the US Atlantic margin and implications for magmatism during continental break-up. Nature, 364:433-436.

Le Maitre R.W. 2003. A classification of igneous rocks and glossary terms. Blackwell Science Publishers., Oxford, $193 p$.

Macciotta G., Almeida A., Barbieri M., Beccaluva L., Brotzu P., Coltorti M., Conte A., Garbarino C., Gomes C.B., Morbidelli L., Ruberti E., Siena F., Traversa G. 1990. Petrology of the tephrite-phonolite suit and cognate xenoliths of the Fortaleza district (Ceará, Brazil). European Journal of Mineralogy, 2:687-709.

McDonough W.F. \& Sun S. 1995. The composition of Earth. Chemical Geology, 120:223-253.

Michard A., Gurriet P., Soudant M., Albared F. 1985. Nd isotopes in French Phanerozoic shales: external vs. internal aspects of crust evolution. Geochimica et Cosmochimica Acta, 49:601-610.

Molina E.C. \& Ussami N. 1999. The geiod in the southern 
Brazil and adjacent regions: new constraints on the density distribution and thermal state of lithosphere. Journal of Geodynamics, 28:321-340.

Morbidelli L., Gomes C.B., Beccaluva L., Brotzu P., Conte A.M., Ruberti, E., Traversa G. 1995. Mineralogical, petrological and geochemical aspects of alkaline and alkaline-carbonatite associations from Brazil. Earth-Science Reviews, 39:135-168.

Morbidelli L., Gomes C.B., Beccaluva L., Brotzu P., Conte A.M., Ruberti E., Traversa G. 2000. The Pariquera-Açu K-alkaline complex and Southeastern Brazil lithospheric mantle source characteristics. Journal of Asian Earth Sciences, 18:129-150.

Riccomini C. 1989. O rift continental do sudeste do Brasil. Tese de Doutoramento, Inst. de Geociências, USP, 256p.

Riccomini C. 1995. Padrão de fraturamento do maciço alcalino de Cananéia, Estado de São Paulo: relações com a tectônica mesozóico-cenozóica do sudeste do Brasil. Revista Brasileira de Geociências, 25:79-84.

Riccomini C., Velázquez V.F., Gomes C.B. 2005. Tectonic controls of the Mesozoic and Cenozoic alkaline magmatism in central-southeastern Brazilian Platform. In: Comin-Chiaramonti P. \& Gomes C.B. (eds.) Mesozoic to Cenozoic alkaline magmatism in the Brazilian Platform. São Paulo, Edusp-Fapesp, p.31-56.

Ruberti E., Gomes C.B., Comin-Chiaramonti P. 2005. The alkaline magmatism from the Ponta Grossa Arch. In: Comin-Chiaramonti P. \& Gomes C.B. (eds.) Mesozoic to Cenozoic alkaline magmatism in the Brazilian Platform. São Paulo, Edusp-Fapesp, p.473-522.

Scheibe L.F., Furtado S.M., Comin-Chiaramonti P., Gomes C.B. 2005. Cretaceous alkaline magmatism from Santa Catarina state southern Brazil. In: Comin-Chiaramonti P. \& Gomes C.B. (eds.) Mesozoic to Cenozoic alkaline magmatism in the Brazilian Platform. São Paulo, EduspFapesp, p. 523-571.

Sheth H.C. 1999. Flood basalts and large igneous provinces from deep mantle plumes: fact, fiction and fallacy. Tectonophysics, 311:1-29.

Siga Jr. O., Gomes C.B., Sato K., Passarelli C.R. 2007. O maciço alcalino de Tunas, PR: novos dados geocronológicos. Geologia USP: Série Científica, 7:71-80.

Smith A.D. \& Lewis C. 1999. The planet beyond the plume hypothesis. Earth Science Reviews, 48:135-182.

Sørensen H. 1960. On the agpaitic rocks. In: International Geological Congress, 21, Norway, XXI Session, Part XIII, p.319-327.

Spinelli F.P. 2003. As rochas alcalinas de Cananéia, Litoral Sul do Estado de São Paulo: características petrográficas, mineralógicas e geoquímicas. Dissertação de Mestrado, Instituto de Geociências, USP, 134p.

Spinelli F.P. 2007. As rochas alcalinas de Cananéia, Litoral Sul do Estado de São Paulo: estudos mineralógicos, geoquímicos e isotópicos. Tese de Doutoramento, Instituto de Geociências, Universidade de São Paulo, 139p.

Spinelli F.P. \& Gomes C.B. 2008. A ocorrência alcalina de Cananéia, litoral sul do Estado de São Paulo: 1. Geologia e Geocronologia. Geologia USP: Série Científica, 8:53-64.

Spinelli F.P. \& Gomes C.B. 2009. A ocorrência alcalina de
Cananéia, litoral sul do Estado de São Paulo: 2. Química mineral. Geologia USP: Série Científica, 9:1-13.

Spinelli F.P., Gomes C.B., Velázquez V.F., Riccomini C., Comin-Chiaramonti P. 2001. Considerações petrográficas e geoquímicas sobre a intrusão alcalina de Cananéia, litoral sul de São Paulo. In: Congresso Brasileiro de Geoquímica, 8 e Simpósio de Geoquímica dos Países do Mercosul, 1, Curitiba, Anais (CD-ROM).

Suguio K. \& Tessler M.G. 1992. Depósitos quaternários da planície costeira de Cananéia-Iguape (SP). Publicação Especial do IO-USP, 9:1-33.

Suguio K., Tessler M.G., Furtado V.V., Esteves C.A., Souza L.A.P. 1987. Perfilagens geofísicas e sedimentação na área submersa entre Cananéia e Barra de Cananéia. In: Simpósio sobre Ecossistemas da Costa Sul e Sudeste Brasileira, 1, Cananéia. ACIESP Publicação, 54-II (2):234-241.

Thompson R.N., Gibson S.A., Mitchell J.G., Dickin A.P., Leonardos O.H., Brod J.A., Greenwood J.C. 1998. Migrating Cretaceous-Eocene magmatism in the Serra do Mar Alkaline Province, SE Brazil: melts form the deflected Trindade mantle plume? Journal of Petrology, 39:14931526.

Thornton C.P. \& Tuttle O.F. 1960. Chemistry of igneous rocks differentiation index. American Journal of Science., 258:664-684.

Traversa G., Barbieri M., Beccaluva L., Coltorti M., Conte A.M., Garbarino C., Gomes C.B., Macciotta G., Morbidelli L., Ronca S., Scheibe L.F. 1996. Mantle sources and differentiation of alkaline magmatic suite of Lages, Santa Catarina, Brazil. European Journal of Mineralogy., 8:193-208.

Ulbrich H.H.G.J., Demaiffe D., Vlach S.R., Ulbrich N.M.C. 2003. Geochemical and $\mathrm{Sr}, \mathrm{Nd}$ and $\mathrm{Pb}$ isotope signatures of phonolites and nepheline syenites from the Poços de Caldas alkaline massif, southeastern Brazil. In: South American Symposium of Isotope Geology, 4, Salvador, Extended Abstracts, p.698-701.

Van Decar J.C., James D.E., Assumpção M. 1995. Seismic evidence for a fossil mantle plume beneath South America and implications for plate driving forces. Nature, 378:25-31.

Vasconcellos E.M.G. \& Gomes C.B. 1998. Diques e plugs alcalinos da região do Vale do Ribeira, divisa dos Estados do Paraná e São Paulo: características petrográficas e geoquímicas. Geochimica Brasiliensis, 12:123-143.

Velázquez V.F., Comin-Chiaramonti P., Cundari, A., Gomes C.B., Riccomini C. 2006. Cretaceous Na-alkaline magmatism from Misiones province (Paraguay): relationships with the Paleogene Na-alkaline analogue from Asunción and geodynamic significance. Journal of Geology, 114:593-614.

Watson E.B. \& Harrison T.M. 1984. Zircon saturation revisited temperature and composition effects in a variety crustal magma types. Earth and Planetary Science Letters, 64:295-304.

Manuscrito ID 11849

Submetido em 23 de julho de 2008 Aceito em 24 de junho de 2009 